\title{
Capital and Labor Income Pareto Exponents across Time and Space*
}

\author{
Tjeerd de Vries ${ }^{\dagger} \quad$ Alexis Akira Toda ${ }^{\ddagger}$
}

June 8, 2021

\begin{abstract}
We estimate capital and labor income Pareto exponents across 475 countryyear observations that span 52 countries over half a century (1967-2018). We document two stylized facts: (i) capital income is more unequally distributed than labor income in the tail; namely, the capital exponent (13 , median 1.46) is smaller than labor (2-5, median 3.35), and (ii) capital and labor exponents are nearly uncorrelated. To explain these findings, we build an incomplete market model with job ladders and capital income risk that gives rise to a capital income Pareto exponent smaller than but nearly unrelated to the labor exponent. Our results suggest the importance of distinguishing income and wealth inequality.
\end{abstract}

Keywords: income fluctuation problem, inequality, power law.

JEL codes: C46, D15, D31, D52.

\section{Introduction}

The purpose of this paper is to estimate and document the Pareto exponents for capital and labor income separately for as many countries and years as possible. We say that a positive random variable $X$ obeys a power law with Pareto exponent $\alpha>0$ if the tail probability decays like a power function: $\mathrm{P}(X>x) \sim x^{-\alpha}$ for

\footnotetext{
${ }^{*}$ We thank Xavier Gabaix, Yannick Hoga, and Makoto Nirei for comments and suggestions.

${ }^{\dagger}$ Department of Economics, University of California San Diego. Email: tjdevrie@ucsd.edu.

${ }^{\ddagger}$ Department of Economics, University of California San Diego. Email: atoda@ucsd.edu.
} 
large $x .^{1}$ In the context of the income distribution, the Pareto exponent characterizes the tail heaviness of high incomes and hence top tail inequality. We remain agnostic about the shape of the income distribution away from the tail. Our study is motivated by the following two observations. First, we are not aware of a comprehensive study that documents the capital and labor income Pareto exponents separately for many countries and years, despite their importance. Second, the Pareto exponent has desirable properties relative to other popular inequality measures such as the Gini coefficient or top income shares.

Consider the first point. Conceptually, capital and labor income are different entities. While the former is the return for providing capital (wealth), the latter is the return for providing labor services, and there is no particular reason to expect a relation between the two. Although these two forms of income are conceptually distinct, it is often put together as just "income" and discussed in the context of inequality and related policies. If capital and labor income are quantitatively different, a policy design based on total income may be misleading. To give one example, consider the theory of optimal taxation (Saez, 2001), where the income Pareto exponent plays an important role. Saez and Stantcheva (2018) carefully distinguish capital and labor income and apply the theory of optimal taxation in the United States. They find that with an income elasticity of $e=0.5$, the optimal top marginal tax rate is about $50 \%$ for labor and $60 \%$ for capital (see their Figure $5)$. This difference directly comes from the fact that capital and labor income Pareto exponents are distinct. Thus, distinguishing capital and labor income inequality is potentially important for policy designs.

Consider the second point about the desirable properties of Pareto exponents. In the applied literature such as Piketty (2003) and Piketty and Saez (2003), top income shares (such as the top $1 \%$ income share) are more commonly reported than the income Pareto exponent, perhaps because top shares are summary statistics that can be computed without specifying functional forms or can be understood by non-experts without special knowledge of statistics. However, Atkinson (2005) documents methodological problems regarding the cross-country comparison of top income shares, citing the differences in tax units (e.g., individual or household) and legislation (e.g., whether social security benefits are taxable). One of the reasons such issues arise is because it is not always clear how to define the population

\footnotetext{
${ }^{1}$ More precisely, we say that a random variable $X$ has a Pareto upper tail with exponent $\alpha>0$ if $\mathrm{P}(X>x)=x^{-\alpha} \ell(x)$ for some slowly varying function $\ell$. A function $\ell:(0, \infty) \rightarrow \mathbb{R}$ is said to be slowly varying (at infinity) if it is nonzero for sufficiently large $x$ and $\lim _{x \rightarrow \infty} \ell(t x) / \ell(x)=1$ for each $t>0$. See Bingham, Goldie, and Teugels (1987) for a comprehensive treatment of the theory of regular variation.
} 
and measure small units. ${ }^{2}$ Because common inequality measures such as the Gini coefficient and top income shares require the knowledge of the entire distribution, these quantities are greatly affected by the definition and measurement of small units. Using the Pareto exponents significantly alleviates these definition and measurement issues because the Pareto distribution is scale invariant (see Jessen and Mikosch, 2006 for a summary) and its exponent depends only on the tail behavior, not the entire distribution. For example, doubling the income of all households in the top $1 \%$ of the income distribution makes the top $1 \%$ income share (roughly) twice as large, but the Pareto exponent is unaffected. A similar comment applies to any inequality measure that depends on the entire distribution, such as the Gini coefficient. While we do not claim that the Pareto exponent is the only interesting inequality measure, it is certainly a robust (detail-independent) measure for top tail inequality. See Gabaix $(2009,2016)$ for more discussion on the robustness of the Pareto distribution.

In this paper, we use the harmonized Luxembourg Income Study database (hereafter LIS) to document the capital and labor income Pareto exponents across all available 475 country-year observations that span 52 countries over half a century. We document two empirical findings. First, we find that the capital income Pareto exponent is roughly in the range 1-3 (with median 1.46) and is smaller than the labor income Pareto exponent, which ranges between 2-5 (with median 3.35). This implies that capital income is more unequally distributed than labor income. This fact is unsurprising and well known for a specific country or year (see, for example, the Lorenz curve in Figure 1 of Saez and Stantcheva, 2018). However, we are not aware of a comprehensive study that systematically analyzes datasets from many countries and years, and therefore our finding suggests that capital income is generally more unequal than labor income. More specifically, using a statistical test recently developed by Hoga (2018), we formally test the equality of capital and labor income Pareto exponents and the null is rejected in $86 \%$ of samples. In every single case of rejection, the capital exponent is smaller than the labor exponent. Second, we find that the capital income Pareto exponent is nearly unrelated to the labor exponent. In particular, the correlation between the two exponents across countries is close to zero.

To explain our empirical findings, we build a simple incomplete market model with job ladders and capital income risk. In the model, agents get randomly

\footnotetext{
${ }^{2}$ Imagine how to formally distinguish cities, towns, villages, and settlements; continents, islands, and islets; and inland seas, lakes, and ponds. How to define units and how to measure small units matter for the size distribution of population, land mass, and water surface area.
} 
promoted to the next job ladder. Because individual income follows a random multiplicative process, we obtain a Pareto-tailed labor income distribution. The agents also save assets and face idiosyncratic investment risk, which generates a Pareto-tailed wealth (hence capital income) distribution. Because the capital income Pareto exponent is mainly determined by the asset return distribution, while the labor income Pareto exponent is mainly determined by the income growth distribution, the relation between the two is weak. Furthermore, we analytically characterize the capital and labor income Pareto exponents and show that the former tends to be smaller than the latter for common parametrization. Our results suggest the importance of distinguishing income and wealth inequality.

Related literature The power law behavior of income was first recognized by Pareto $(1895,1896,1897)$, who used tabulation data of tax returns in many European countries. More recent research that employs micro data include Reed (2001) for U.S., Reed (2003) for U.S., Canada, Sri Lanka, and Bohemia, Nirei and Souma (2007) for Japan, Toda (2011, 2012) for U.S., Jenkins (2017) for U.K., and Ibragimov and Ibragimov (2018) for Russia. These papers all concern specific countries and years. Bandourian, McDonald, and Turley (2003) estimate eleven parametric distributions (some of which exhibit Pareto tails) using 82 household labor income datasets from Luxembourg Income Study (LIS) as we do, though they neither focus on the Pareto exponent nor consider capital income. Gabaix (2009) mentions "[the] tail exponent of income seems to vary between 1.5 and 3", citing Atkinson and Piketty (2007), though without providing specific details. Atkinson and Piketty (2010, Table 13A.23) document income Pareto exponents across many countries and years estimated from top income share data based on tax returns. However, these estimates are computed from total income, and since (as we document in Section 3.3) the capital income Pareto exponents tend to be smaller than labor exponents, their estimates are best understood as capital income (hence wealth) Pareto exponents. Benhabib, Bisin, and Luo (2017) make the point that wealth is more skewed than income, citing a few Pareto exponent estimates from Badel, Daly, Huggett, and Nybom (2018) for income and Vermeulen (2018) for wealth. Using the 2013-2014 individual income tax data from Romania, Oancea, Pirjol, and Andrei (2018) document that the capital income Pareto exponent (1.44) is smaller than the labor exponent (2.53). Using time series regressions for 21 countries, Bengtsson and Waldenström (2018) document a positive correlation between the gross capital share in national accounts and the top $1 \%$ income shares. Their finding can be explained if top income earners tend to have higher 
capital income share, which is the case if the capital income Pareto exponent is smaller than the labor exponent as we document in this paper. As mentioned in the introduction, there seems to be no comprehensive studies that document the capital and labor income Pareto exponents separately for many countries and years.

\section{Data}

In this section we describe the dataset that we use and discuss its limitations.

\subsection{The LIS database}

We use the data from the Luxembourg Income Study (LIS), which is a large, harmonized database of micro-level income data that covers over 50 countries worldwide and many years since the late 1960s. In many countries, the data derive from government surveys (for example, the U.S. data is based on the Current Population Survey). The LIS data are available at both individual and household level. We focus on the household labor and capital income because (i) it is reasonable to assume that economic decisions such as financial planning are made at the household level, and (ii) incomes among couples are likely correlated due to assortative matching in the marriage market (Siow, 2015), which invalidates statistical estimation. ${ }^{3}$ The LIS defines labor income as "cash payments and value of goods and services received from dependent employment, as well as profits/losses and value of goods from self-employment, including own consumption". Capital income is defined as "cash payments from property and capital (including financial and nonfinancial assets), including interest and dividends, rental income and royalties, and other capital income from investment in self-employment activity". Together these two categories make up total factor income. See the LIS 2019 USER GUIDE $^{4}$ for a detailed summary on how these data are retrieved and calculated.

\subsection{Data limitations}

Our analysis draws upon datasets from many different countries that are harmonized into a common framework by the LIS. However, many details about the collection of data in the different countries are omitted. For example, we find

\footnotetext{
${ }^{3}$ In our data, we find an average correlation of 0.22 between labor income of husband and wife, which underpins the conjectured dependency.

${ }^{4}$ https://www.lisdatacenter.org/wp-content/uploads/files/data-lis-guide.pdf
} 
evidence of top-coding in some countries and years, as the largest income order statistic is equal to the second largest. ${ }^{5}$ Top-coding induces an upward bias in the estimation of the Pareto exponent. This issue is not necessarily resolved if, instead, one relies on administrative tax income data, for similar biases arise such as rich households trying to understate their taxable income (Atkinson, Piketty, and Saez, 2011). Burkhauser, Feng, Jenkins, and Larrimore (2012) detail a method that can be used to overcome the bias due to top-coding, however at the end of their paper they show that the results are robust even if estimates are based on the top-coded series. For these reasons we treat the datasets as not being top-coded in our analysis.

Another limitation of the LIS database is that it is based on government surveys and the measurement error may be larger compared to administrative data based on tax returns. The fact that the income distribution in administrative data is often reported as tabulations, not micro data, causes no problem for estimating Pareto exponents, as Toda and Wang (2021) provide an efficient estimation method for such data. In fact, Atkinson and Piketty (2010, Table 13A.23) document income Pareto exponents across countries and years estimated from top income share data. However, their table is based on total income, and since (as we document in Section 3.3) the capital income Pareto exponents tend to be smaller than labor exponents, the estimates in Atkinson and Piketty (2010) are best understood as capital income (hence wealth) Pareto exponents. Since we are not aware of a comprehensive income database that distinguishes capital and labor income, we decided to use the LIS database.

\section{Pareto exponents across countries and years}

In this section we estimate the capital and labor income Pareto exponents for all countries and years that are available in the LIS database, which spans 52 countries over half a century (475 country-year observations in total). We then formally test for the equality of the Pareto exponents of capital and labor income.

\subsection{Estimation method}

For each country and year, we suppose that the (capital or labor) income observations $\left\{X_{n}\right\}_{n=1}^{N}$ are independent and identically distributed (IID) with cumulative

\footnotetext{
${ }^{5}$ Among all 475 country-year observations, the first and second order statistics are equal in 6 cases for labor income and 11 cases for capital income. Therefore we conjecture that the top-coding issue is not severe.
} 
distribution function $(\mathrm{CDF}) F(x)=\mathrm{P}\left(X_{n} \leq x\right)$. The assumption that the upper tail of income obeys a power law with Pareto exponent $\alpha>0$ translates into the regular variation condition

$$
1-F(x)=x^{-\alpha} \ell(x)
$$

for some slowly varying function $\ell$ (see Footnote 1 ). Note that the assumption on $\ell$ involves only the limit as $x \rightarrow \infty$; we are assuming a power law behavior in the upper tail without taking a stance on the shape of the entire distribution.

We are interested in estimating the Pareto exponent $\alpha$ for each country and year. For this purpose, we employ the Hill (1975) (maximum likelihood) estimator

$$
\frac{1}{\widehat{\alpha}(k)}:=\frac{1}{k} \sum_{n=1}^{k} \log \left(\frac{X_{(n)}}{X_{(k)}}\right) .
$$

Here $X_{(n)}$ denotes the $n$-th largest order statistic from the sample $\left\{X_{n}\right\}_{n=1}^{N}$ and $k \in\{1, \ldots, N\}$ denotes the number of tail observations used to estimate the Pareto exponent. Hall (1982) shows that the standard error of $\widehat{\alpha}(k)$ is $\widehat{\alpha}(k) / \sqrt{k}$ under flexible assumptions on the CDF (see (3.3) below). We use the Hill estimator because we are interested in formally testing the equality of the capital and labor income Pareto exponents using the method of Hoga (2018), for which the Hill estimator is required. ${ }^{6}$

When the population distribution is known to be exactly Pareto (so $\ell$ in (3.1) is zero below the minimum size $x_{\text {min }}$ and constant above this threshold), it is well known that the Hill estimator for the full sample $(k=N)$ is consistent, asymptotically normal, and asymptotically efficient because it is a maximum likelihood estimator. In practice, the CDF is not exactly Pareto and the researcher needs to select an appropriate value of $k$. For instance, if $F(x)$ satisfies

$$
1-F(x)=C x^{-\alpha}\left(1+D x^{-\beta}+o\left(x^{-\beta}\right)\right)
$$

with some $\beta>0$, then Hall (1982) shows that choosing $k=o\left(N^{2 \beta /(2 \beta+\alpha)}\right)$ together with $k \rightarrow \infty$ as $N \rightarrow \infty$ is sufficient for consistency and asymptotic normality (see also Embrechts, Klüppelberg, and Mikosch, 2013). ${ }^{7}$ Notice that this choice

\footnotetext{
${ }^{6}$ If we are only interested in estimating the Pareto exponents, then there are many alternative methods available. Gomes and Guillou (2015) review 13 commonly used estimators. Fedotenkov (2020) reviews more than 100 .

${ }^{7}$ Recall that we write $f(x)=o(g(x))$ if for all $\epsilon>0$, we have $|f(x)| \leq \epsilon|g(x)|$ for large enough $x$.
} 
puts a bound on the growth rate of $k$. The expansion (3.3) covers a wide range of distributions of interest, such as the $t$-distribution and the type II extreme value distribution (Daníelsson and de Vries, 1997).

Despite these asymptotic results, it is notoriously difficult to pick $k$ optimally in finite samples (Hall, 1990; Resnick and Stărică, 1997; Danielsson, de Haan, Peng, and de Vries, 2001). In practice, researchers often plot the Hill estimator (3.2) over a range of $k$ to find a flat region or plot the $\log \operatorname{rank} \log 1, \ldots, \log N$ against the $\log$ size $\log X_{(1)}, \ldots, \log X_{(N)}$ to find a region that exhibits a straight line pattern and choose a size threshold to run the log-rank regression. ${ }^{8}$ Unfortunately, this graphical approach is not feasible in our setting because LIS does not allow researchers to download the micro data for confidentiality concerns (researchers are required to submit their execution files to conduct statistical analyses) and there is little scope for exploratory graphical data analysis. In this paper we simply use the largest $5 \%$ observations, so

$$
k=\lfloor 0.05 N\rfloor,
$$

which is standard in the literature. ${ }^{9}$ Unreported simulations show that our results are robust to using other thresholds such as the largest $1 \%$ and $10 \%$ observations, or using a data-driven procedure using the Kolmogorov-Smirnov distance as in Danielsson, Ergun, de Haan, and de Vries (2016).

\subsection{Capital and labor income Pareto exponents}

We estimate the capital and labor income Pareto exponents for all countries and years available in the LIS database. The database spans 52 countries across the years 1967-2018, with a total of 475 country-year observations. The point estimates of the capital and labor income Pareto exponents for each country and year as well as their standard errors can be found in Table 2 in Appendix C. To

\footnotetext{
${ }^{8}$ Gabaix and Ibragimov (2011) study the asymptotic behavior of log rank regression and show that the standard error is larger by a factor of $\sqrt{2}$ than the Hill estimator. However, they do not discuss how to select the threshold. In their empirical application, they consider the size distribution of population in U.S. metropolitan statistical areas, which are already far into the tail and hence the threshold selection is less of an issue. Ibragimov and Ibragimov (2018) apply the same methodology to Russian household income data and consider the top $5 \%$ and $10 \%$ thresholds.

${ }^{9}$ An alternative approach is to estimate a parametric distribution $F$ that admits a Pareto upper tail by maximum likelihood using the entire sample. The double Pareto-lognormal distribution proposed by Reed (2003) and Reed and Jorgensen (2004) often performs best. See Toda (2012) for a horse race across several parametric distributions in the context of U.S. labor income.
} 
avoid small sample issues, we restrict our analysis to countries with at least 1,000 positive observations for income, resulting in (all) 475 country-year pairs for labor income and 342 for capital income. For visibility, Figure 1 shows the histogram and scatter plot of the capital and labor income Pareto exponents.

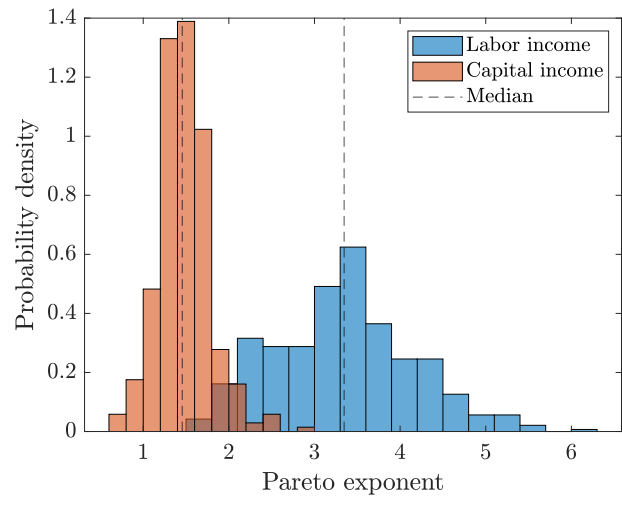

(a) Histogram.

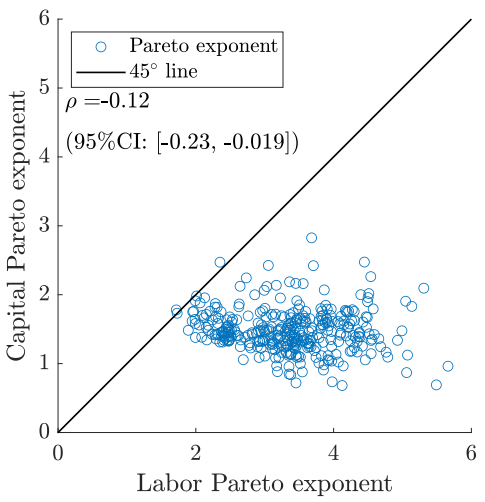

(b) Scatter plot.

Figure 1: Histogram and scatter plot of capital and labor income Pareto exponents.

Figure 1a shows the histogram of the capital and labor income Pareto exponents pooled across all available countries and years. The capital and labor income Pareto exponents are generally in the range 1-3 and 2-5 with medians 1.46 and 3.35, respectively. This suggests that (i) capital income is generally more unequally distributed than labor income, but (ii) there is significant heterogeneity in both capital and labor income inequality across countries and years. Figure $1 \mathrm{~b}$ shows the scatter plot of the Pareto exponents together with the 45 degree line. The confidence interval of the correlation coefficient $\rho$ is computed assuming all country-year observations are independent and there is no sampling error in the point estimates of the Pareto exponents. Although it is not obvious how to account for these issues, doing so will only widen the confidence interval. Therefore the fact that the naïve confidence interval almost contains zero suggests that the correlation between the two Pareto exponents is weak. Furthermore, for the vast majority of countries and years, the capital income Pareto exponent is smaller than the labor exponent, again suggesting that capital income is more unequal than labor income.

How do the Pareto exponents evolve over time? Because many countries appear only sporadically in the LIS database, we only consider six countries for which the cross-sectional sample size is large and the time series is long, namely Canada, Germany, Switzerland, Taiwan, United Kingdom, and United States. Figure 2 plots the capital and labor Pareto exponents and their $95 \%$ confidence intervals 
for these countries. The capital exponent tends to be stable at around 1-2 and is smaller than the labor exponent. ${ }^{10}$ Again, capital income appears to be more unequally distributed than the labor income.
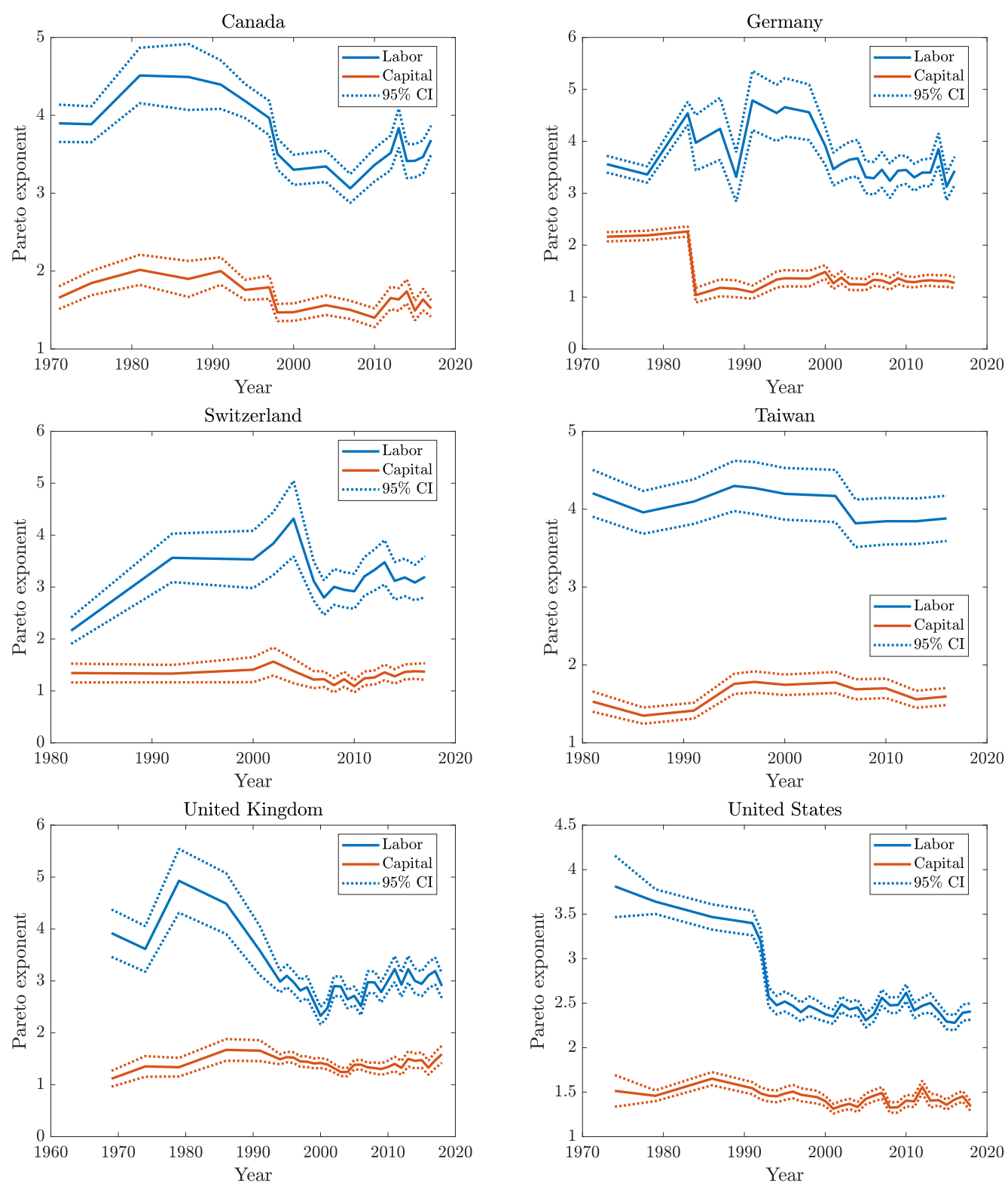

Figure 2: Time evolution of capital and labor income Pareto exponents.

\footnotetext{
${ }^{10}$ An exception may be Germany before 1983 . However, this may be an artifact of the sudden change in sample size, which was over 40,000 until 1983 and about 5,000 since 1984. Thus the $5 \%$ rule for capital income may be including too many observations in the body of the distribution before 1983.
} 


\subsection{Testing equality of capital and labor Pareto exponents}

We now formally test whether the capital and labor Pareto exponents are equal. In particular our test is

$$
H_{0}: \alpha_{\text {lab }}=\alpha_{\text {cap }} \text { against } \quad H_{1}: \alpha_{\text {lab }} \neq \alpha_{\text {cap }}
$$

where $\alpha_{\text {cap }}, \alpha_{\text {lab }}$ denote the capital and labor income Pareto exponents. Testing the null hypothesis $H_{0}$ is complicated by the fact that there is dependency between labor income $\left\{X_{\text {lab }, n}\right\}_{n=1}^{N}$ and capital income $\left\{X_{\text {cap }, n}\right\}_{n=1}^{N}$, because individuals who are rich (receive high labor income) tend to be wealthy and receive high capital income. Thus we cannot use the 95\% confidence intervals in Figure 2 to test the equality of Pareto exponents. Instead, we apply the test recently developed by Hoga (2018), which allows for dependence in the data but assumes restrictions on the growth rate of the tail dependence (see Hoga, 2018, Assumption A2). The test is based upon the inverse of the Hill estimator (3.2), which we denote by $\widehat{\gamma}:=1 / \widehat{\alpha}$. The test statistic is defined by

$$
T_{N}=\frac{\left(\widehat{\gamma}_{\text {lab }}(1)-\widehat{\gamma}_{\text {cap }}(1)\right)^{2}}{\int_{t_{0}}^{1} t^{2}\left[\left(\widehat{\gamma}_{\text {lab }}(t)-\widehat{\gamma}_{\text {cap }}(t)\right)-\left(\widehat{\gamma}_{\text {lab }}(1)-\widehat{\gamma}_{\text {cap }}(1)\right)\right]^{2} \mathrm{~d} t},
$$

where $t_{0} \in(0,1)$ is a tuning parameter and $\widehat{\gamma}(t)$ is the inverse Hill estimator

$$
\widehat{\gamma}(t):=\frac{1}{\lfloor k t\rfloor} \sum_{n=1}^{\lfloor k t\rfloor} \log \left(\frac{X_{(n)}}{X_{(\lfloor k t\rfloor)}}\right) .
$$

Using the Hill estimator based on the subsample with only $\lfloor k t\rfloor$ observations leads to self-normalization of the test statistic $T_{N}$ and renders a test that is asymptotically pivotal. The limiting distribution is

$$
T_{N} \stackrel{\mathrm{d}}{\rightarrow} \frac{W(1)^{2}}{\int_{t_{0}}^{1}[W(t)-t W(1)]^{2} \mathrm{~d} t},
$$

where $W(t)$ is a standard Brownian motion. Since the test statistic (3.5) can be computed using only the Hill estimator and conducting numerical integration, there is no need to estimate the (potentially difficult) tail covariance. The tuning parameter $t_{0}$ affects the size of the test in finite samples: high values of $t_{0}$ make the integral in (3.5) based on too few differences of $\widehat{\gamma}$, and low values of $t_{0}$ yield volatile $\widehat{\gamma}$ in (3.6) when $t$ is close to $t_{0}$. Both of these effects may cause size distortions. Therefore we set $t_{0}=0.2$ following the recommendation of Hoga (2018), who finds 
that this choice leads to favorable size properties. ${ }^{11}$ We reject the null $H_{0}$ when the test statistic $T_{N}$ is large. According to Table I of Hoga (2018), the 95 percentile of (3.7) for $t_{0}=0.2$ is 55.44 , which we use as the critical value for testing $H_{0}$ at $5 \%$ significance level.

One issue with the test statistic (3.5) is that it requires the same number of tail observations $k$ for both cross-sections of capital and labor income. Hence the $5 \%$ rule (3.4) discussed in Section 3.1 becomes problematic as the number of people with capital income in our data set is rather small. Many households do not hold liquid financial wealth and hence have no capital income. The resulting test is thus not feasible since $k_{\text {lab }}$ based on our $5 \%$ rule could be wildly different from $k_{\text {cap }}$. To overcome this issue, we only test the equality of Pareto exponents for countries that have more than 1,000 positive capital income observations and set $k=\left\lfloor 0.05 N_{\text {cap }}\right\rfloor$, where $N_{\text {cap }}$ is the number of positive capital income observations (these households always have positive labor income), resulting in 342 countryyear observations out of 475 . In practice this means that we estimate the Pareto exponent of labor income further in the tail because the sample size of labor income $N_{\text {lab }}$ tends to be larger than $N_{\text {cap }}$. However, this is acceptable since the Pareto approximation tends to fit better for smaller $k$. Figure 3 presents a scatter plot of the estimated labor income Pareto exponent $\widehat{\alpha}_{\text {lab }}$ using $5 \%$ of the full sample $\left(N_{\text {lab }}\right)$ and $5 \%$ of the sample with positive capital income $\left(N_{\text {cap }}\right)$. The fact that most points are close to the 45 degree supports our claim.

Table 3 in Appendix $\mathrm{C}$ shows the test results of the null hypothesis $H_{0}: \alpha_{\text {lab }}=$ $\alpha_{\text {cap }}$. We reject the null in 294 country-year observations out of $342(86 \%)$ that meet our sample selection criterion. In every single case of rejection, we have $\widehat{\alpha}_{\text {lab }}>\widehat{\alpha}_{\text {cap }}$, and therefore we formally confirm the observation in Section 3.2 that capital income is more unequally distributed than labor income.

\section{Model of capital and labor Pareto exponents}

Our empirical analysis in Section 3 suggests that (i) the capital income Pareto exponent is smaller than the labor one (i.e., capital income is more unequally distributed than labor income), and (ii) the correlation between capital and labor income Pareto exponents is weak. To explain these empirical findings, we present a simple dynamic model of consumption and savings, which builds on one of the

\footnotetext{
${ }^{11}$ The choice of $t_{0}$ in Hoga (2018) comes out using an automated selection procedure to choose $k$, which is different than our $5 \%$ rule. An earlier version of our paper employs the same automated procedure, which leads to very similar results.
} 


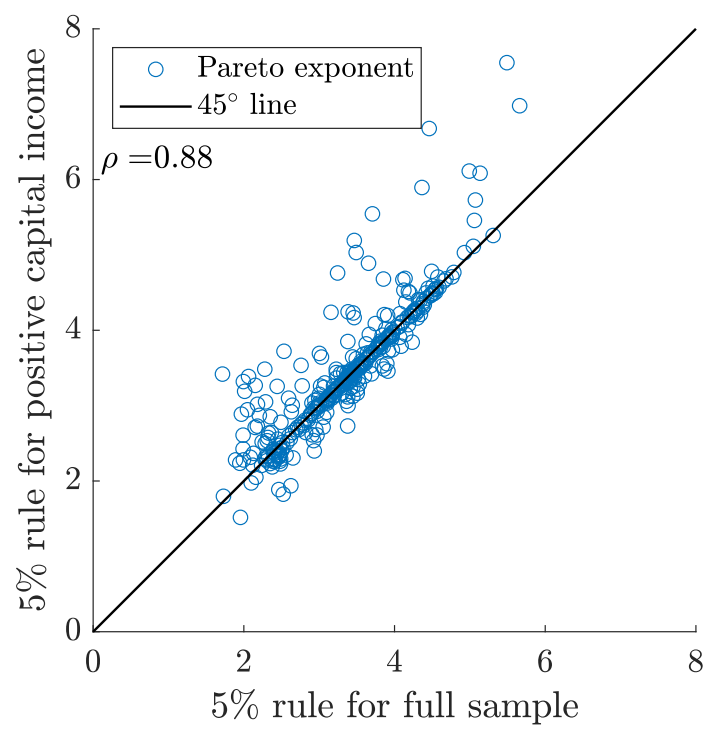

Figure 3: Labor Pareto exponent with full and positive capital income samples.

authors' prior works (Ma, Stachurski, and Toda, 2020; Ma and Toda, 2021). Our model is more specialized but the characterizations are sharper. The proofs of propositions in this section are deferred to Appendix A.

\subsection{Income fluctuation problem}

Time is discrete and denoted by $t=0,1,2, \ldots$ Let $a_{t}$ be the financial wealth of a typical agent at the beginning of period $t$ including current income. The agent chooses consumption $c_{t} \geq 0$ and saves the remaining wealth $a_{t}-c_{t}$. The period utility function is $u:(0, \infty) \rightarrow \mathbb{R}$, the discount factor is $\beta>0$, the gross return on wealth between time $t-1$ and $t$ is $R_{t}>0$, and non-financial income at time $t$ is $Y_{t}>0$. Thus the agent solves

$$
\begin{array}{ll}
\text { maximize } & \mathrm{E}_{0} \sum_{t=0}^{\infty} \beta^{t} u\left(c_{t}\right) \\
\text { subject to } & a_{t+1}=R_{t+1}\left(a_{t}-c_{t}\right)+Y_{t+1}, \\
& 0 \leq c_{t} \leq a_{t},
\end{array}
$$

where the initial wealth $a_{0}=a>0$ is given, (4.1b) is the budget constraint, and (4.1c) implies that the agent cannot borrow (which is without loss of generality according to the discussion in Chamberlain and Wilson, 2000). Throughout the rest of the paper we maintain the following assumptions. 
Assumption 1 (CRRA utility). The utility function exhibits constant relative risk aversion (CRRA) with coefficient $\gamma>0$, so $u(c)=\frac{c^{1-\gamma}}{1-\gamma}$ if $\gamma \neq 1$ and $u(c)=\log c$ if $\gamma=1$.

Assumption 2 (IID shocks). Let $G_{t+1}:=Y_{t+1} / Y_{t}$ be gross growth rate of income. The sequence $\left\{R_{t+1}, G_{t+1}\right\}_{t=0}^{\infty}$ is independent and identically distributed (IID).

These assumptions are similar to Carroll (2020), except that we allow for stochastic returns on savings. Note that the asset return $R_{t+1}$ and income growth $G_{t+1}$ are potentially mutually dependent. Due to the IID assumption, the state variables of the income fluctuation problem (4.1) are financial wealth $a_{t}>0$ and current income $Y_{t}>0$. Exploiting homotheticity (Assumption 1), we can reduce the number of state variables to just one, namely the wealth-income ratio (normalized wealth) $\tilde{a}_{t}:=a_{t} / Y_{t}$. To see this, letting $\tilde{c}_{t}:=c_{t} / Y_{t}$ be the consumption-income ratio (normalized consumption), dividing the borrowing constraint (4.1c) by $Y_{t}$, we obtain $0 \leq \tilde{c}_{t} \leq \tilde{a}_{t}$. Similarly, dividing the budget constraint (4.1b) by $Y_{t+1}$, we obtain

$$
\begin{aligned}
\tilde{a}_{t+1}=a_{t+1} / Y_{t+1} & =\left(R_{t+1} Y_{t} / Y_{t+1}\right)\left(a_{t} / Y_{t}-c_{t} / Y_{t}\right)+1 \\
& =\left(R_{t+1} / G_{t+1}\right)\left(\tilde{a}_{t}-\tilde{c}_{t}\right)+1 \\
& =\tilde{R}_{t+1}\left(\tilde{a}_{t}-\tilde{c}_{t}\right)+1
\end{aligned}
$$

where $\tilde{R}_{t+1}:=R_{t+1} / G_{t+1}$ is the asset return relative to income growth. As for the utility function, since

$$
c_{t}=Y_{t} \tilde{c}_{t}=Y_{0}\left(\prod_{s=1}^{t} G_{s}\right) \tilde{c}_{t}
$$

(here we interpret $\prod_{s=1}^{0} \bullet=1$ ), assuming $Y_{0}=1$ (which is without loss of generality) and $\gamma \neq 1$, it follows from (4.1a) that

$$
\begin{aligned}
\mathrm{E}_{0} \sum_{t=0}^{\infty} \beta^{t} u\left(c_{t}\right) & =\mathrm{E}_{0} \sum_{t=0}^{\infty}\left(\prod_{s=1}^{t} \beta G_{s}^{1-\gamma}\right) \frac{\tilde{c}_{t}^{1-\gamma}}{1-\gamma} \\
& =\mathrm{E}_{0} \sum_{t=0}^{\infty}\left(\prod_{s=1}^{t} \tilde{\beta}_{s}\right) \frac{\tilde{c}_{t}^{1-\gamma}}{1-\gamma}
\end{aligned}
$$

where $\tilde{\beta}_{t}:=\beta G_{t}^{1-\gamma}$. The discussion for $\gamma=1$ is similar. Therefore the problem reduces to an income fluctuation problem with CRRA utility, random discount factors $\left\{\tilde{\beta}_{t}\right\}_{t=1}^{\infty}$, stochastic returns $\left\{\tilde{R}_{t}\right\}_{t=1}^{\infty}$ on wealth, and constant income $\left(\tilde{Y}_{t} \equiv\right.$ 1). The general theory of income fluctuation problems with stochastic discounting, 
returns, and income in a Markovian setting was developed by Ma et al. (2020). Therefore we immediately obtain the following result. In what follows, we drop the time subscript when no confusion arises.

Proposition 1. Suppose Assumptions 1, 2 hold and

$$
\beta \mathrm{E}\left[G^{1-\gamma}\right]<1 \quad \text { and } \quad \beta \mathrm{E}\left[R G^{-\gamma}\right]<1
$$

Then the income fluctuation problem (4.1) has a unique solution. The consumption function can be expressed as $c(a, Y)=Y \tilde{c}(a / Y)$, where $\tilde{c}:(0, \infty) \rightarrow(0, \infty)$ is the consumption function of the detrended problem (maximizing (4.3) subject to (4.2)), which can be computed by policy function iteration. ${ }^{12}$

\subsection{Tail behavior of income and wealth}

We now characterize the tail behavior of income and wealth in the context of the income fluctuation problem in Section 4.1.

To make the model stationary, suppose that agents survive to the next period with probability $v \in(0,1)$ (perpetual youth model as in Yaari, 1965). Whenever agents die, they are replaced by newborn agents. For simplicity, assume that the discount factor $\beta$ in (4.1a) already accounts for survival probability and that there is no market for life insurance (allowing for life insurance only changes $R$ to $R / v$ and is thus mathematically equivalent after reparametrization). Without loss of generality, suppose that newborn agents start with income $Y_{0}=1$. Then the income of a randomly selected agent is $Y_{T}$, where $T$ is a geometric random variable with mean $\frac{1}{1-v}$. By the assumption on income growth, the log income of a randomly selected agent

$$
\log Y_{T}=\log \left(Y_{T} / Y_{0}\right)=\sum_{t=1}^{T} \log G_{t}
$$

is a geometric sum of IID random variables, for which we can characterize the tail behavior as follows.

Proposition 2 (Income Pareto exponent). Suppose that $\mathrm{P}(G>1)>0$ and $1<$ $v \mathrm{E}\left[G^{z}\right]<\infty$ for some $z>0$. Then the cross-sectional income distribution has a Pareto upper tail, whose exponent is the unique positive solution $z=\alpha_{Y}$ to

$$
v \mathrm{E}\left[G^{z}\right]=1 .
$$

\footnotetext{
${ }^{12} \mathrm{See} \mathrm{Li}$ and Stachurski (2014) and Ma et al. (2020) for details on policy function iteration.
} 
Proof. See Beare and Toda (2017, Theorem 3.4).

To characterize the tail behavior of wealth, we first note that the normalized consumption function $\tilde{c}$ in Proposition 1 is concave and asymptotically linear with a specific slope. ${ }^{13}$

Proposition 3 (Concavity and asymptotic linearity). Let everything be as in Proposition 1. Then $\tilde{c}$ is concave and

$$
\lim _{a \rightarrow \infty} \frac{\tilde{c}(a)}{a}= \begin{cases}1-\left(\mathrm{E}\left[\beta R^{1-\gamma}\right]\right)^{1 / \gamma} & \text { if } \mathrm{E}\left[\beta R^{1-\gamma}\right]<1 \\ 0 & \text { otherwise. }\end{cases}
$$

Using Proposition 3 and setting $\rho=\min \left\{\left(\mathrm{E}\left[\beta R^{1-\gamma}\right]\right)^{1 / \gamma}, 1\right\}$, for high enough asset level, the detrended budget constraint (4.2) becomes approximately

$$
\tilde{a}_{t+1} \approx \rho \tilde{R}_{t+1} \tilde{a}_{t}+1
$$

which is a random multiplicative process (Kesten (1973) process). Under specific assumptions, Ma et al. (2020, Theorem 3.3) prove that the upper tail of the stationary distribution of normalized wealth $\tilde{a}_{t}$ has a Pareto lower bound. Although a sharp characterization of the tail behavior is generally difficult, in our setting it is possible to obtain an exact characterization due to concavity and the IID assumption.

Proposition 4. Let $\rho=\min \left\{\left(\mathrm{E}\left[\beta R^{1-\gamma}\right]\right)^{1 / \gamma}, 1\right\}$ and $H=\rho \tilde{R}$. Suppose that (i) $R$ is thin-tailed (meaning $\mathrm{E}\left[R^{z}\right]<\infty$ for all $z>0$ ), (ii) $\log H$ is non-lattice (not supported on an evenly spaced grid), and (iii) $\mathrm{P}(H>1)>0$, and $1<v \mathrm{E}\left[H^{z}\right]<\infty$ for some $z>0$. Then the cross-sectional normalized wealth distribution is either bounded or has a Pareto upper tail, in which case the exponent is the unique positive solution $z=\tilde{\alpha}$ of

$$
v \mathrm{E}\left[H^{z}\right]=1
$$

The Pareto exponent for wealth and capital income is then $\alpha=\min \left\{\tilde{\alpha}, \alpha_{Y}\right\}$.

Proposition 4 is significant despite its simplicity. According to the model, we always have $\alpha \leq \alpha_{Y}$, typically with a strict inequality as we see in the numerical example below. This is in sharp contrast to canonical incomplete market general equilibrium models such as Aiyagari (1994), where agents can save using only a

\footnotetext{
${ }^{13}$ Carroll and Kimball (1996) showed the sufficiency of hyperbolic absolute risk aversion (HARA, which includes CRRA) for the concavity of the consumption function. Toda (2021) proved the necessity.
} 
risk-free asset. In such models, the impossibility theorem of Stachurski and Toda (2019) implies that the tail behavior of income and wealth is the same, implying $\alpha=\alpha_{Y}$ in our setting. ${ }^{14}$ Therefore, unlike canonical incomplete market models, our model can explain the empirical fact that capital income is more unequal than labor income. The key assumption leading to this conclusion is the presence of stochastic returns.

We discuss an analytically solvable example to build intuition.

Example 1. Let $\Delta>0$ be the length of time of one period and the discount factor be $\beta=\mathrm{e}^{-\delta \Delta}$, where $\delta>0$ is the discount rate. Suppose income grows at a constant rate $g>0$, so $G=\mathrm{e}^{g \Delta}$. Suppose asset return is risk-free, so $R=\mathrm{e}^{r \Delta}$ with $r>0$. Finally, let the survival probability be $v=\mathrm{e}^{-\eta \Delta}$, where $\eta$ is the death rate. Then (4.5) becomes

$$
1=\mathrm{e}^{-\eta \Delta} \mathrm{e}^{z g \Delta} \Longleftrightarrow z=\eta / g
$$

so the income Pareto exponent is $\alpha_{Y}=\eta / g$. (This is the classical result of Wold and Whittle (1957) in discrete-time.) Suppose in addition that $-\eta+r(1-\gamma)<0$ so that $\beta R^{1-\gamma}<1$. Since

$$
H=\left(\mathrm{E}\left[\beta R^{1-\gamma}\right]\right)^{1 / \gamma} \tilde{R}=(\beta R)^{1 / \gamma} / G=\mathrm{e}^{\left(\frac{r-\eta}{\gamma}-g\right) \Delta},
$$

solving (4.7) the normalized wealth Pareto exponent is

$$
\tilde{\alpha}=\frac{\eta \gamma}{r-\eta-g \gamma}
$$

assuming $r-\eta-g \gamma>0$. Therefore

$$
\tilde{\alpha}<\alpha_{Y} \Longleftrightarrow \frac{\eta \gamma}{r-\eta-g \gamma}<\frac{\eta}{g} \Longleftrightarrow r>\eta+2 g \gamma
$$

so the wealth (hence capital income) Pareto exponent is smaller than the labor income Pareto exponent if the return on wealth $r$ is sufficiently large. In summary, we obtain the following result: suppose $-\eta+r(1-\gamma)<0$ and let $\alpha_{\text {cap }}, \alpha_{\text {lab }}$ be the capital and labor income Pareto exponents. Then

$$
\begin{cases}\alpha_{\text {cap }}=\alpha_{\text {lab }}=\frac{\eta}{g} & \text { if } r \leq \eta+2 g \gamma, \\ \alpha_{\text {cap }}=\frac{\eta \gamma}{r-\eta-g \gamma}<\frac{\eta}{g}=\alpha_{\text {lab }} & \text { if } r>\eta+2 g \gamma .\end{cases}
$$

\footnotetext{
${ }^{14}$ The original proof in Stachurski and Toda (2019) contained an error; it has been corrected in Stachurski and Toda (2020).
} 
Note that the labor income Pareto exponent $\alpha_{\mathrm{lab}}=\eta / g$ is highly sensitive to the income growth rate $g$. However, provided that $r>\eta+2 g \gamma$, the capital income Pareto exponent $\alpha_{\text {cap }}$ is not very sensitive to the value of $g$ because the denominator is $r-\eta-g \gamma$. This example is consistent with our result in Section 3.2 that the capital Pareto exponent is smaller than the labor Pareto exponent but the two values are only weakly related.

\subsection{Numerical example}

We further examine the tail behavior of income and wealth using a numerical example of the income fluctuation problem (4.1). Suppose that asset return is IID lognormal, so $\log R \sim N\left(\left(\mu-\sigma^{2} / 2\right) \Delta, \sigma^{2} \Delta\right)$, where $\Delta>0$ is the length of one period, $\mu$ is the expected return, and $\sigma$ is volatility. Suppose every period the agent is "promoted" with some probability, so the income growth rate is

$$
G_{t+1}=Y_{t+1} / Y_{t}= \begin{cases}1 & \text { with probability } 1-p \\ \mathrm{e}^{g} & \text { with probability } p\end{cases}
$$

where $p \in(0,1)$ is the promotion probability and $g$ is the log income growth rate conditional on promotion. We parametrize the promotion probability as $p=$ $1-\mathrm{e}^{-\Delta / L}$, where $L$ is the expected length of time until a promotion. Using (4.5), the labor income Pareto exponent is determined such that

$$
1=v \mathrm{E}\left[G^{\alpha_{Y}}\right]=v\left(1-p+p \mathrm{e}^{g \alpha_{Y}}\right) \Longleftrightarrow \alpha_{Y}=\frac{1}{g} \log \frac{1-v+v p}{v p} .
$$

We set the parameter values as in Table 1. One unit of time corresponds to a year and one period is a quarter, so $\Delta=1 / 4$. The preference parameters (discount rate and risk aversion) are standard. The death rate of $\eta=0.025 \mathrm{implies}$ an average (economically active) age of $1 / \eta=40$ years. The expected return and volatility roughly correspond to the stock market. We set the labor income Pareto exponent to $\alpha_{Y}=3$, which is roughly the median value in Figure 1. Using the survival probability $v=\mathrm{e}^{-\eta \Delta}$ and (4.9), the implied value of income growth upon promotion is $g=0.0403$. The wealth Pareto exponent determined by (4.7) is then $\alpha=1.201$.

To numerically solve the income fluctuation problem (4.1), we discretize the $\log$ asset return $\log R$ using a 7-point Gauss-Hermite quadrature and apply policy function iteration (see Appendix B). After solving the individual problem, we apply the Pareto extrapolation algorithm developed in Gouin-Bonenfant and Toda 
Table 1: Parameter values

\begin{tabular}{lcc}
\hline Parameter & Symbol & Value \\
\hline Length of one period & $\Delta$ & $1 / 4$ \\
Discount rate & $\delta$ & 0.04 \\
Relative risk aversion & $\gamma$ & 2 \\
Death rate & $\eta$ & 0.025 \\
Expected return & $\mu$ & 0.07 \\
Volatility & $\sigma$ & 0.15 \\
Expected time to promotion & $L$ & 5 \\
Labor income Pareto exponent & $\alpha_{Y}$ & 3 \\
\hline
\end{tabular}

(2018) to accurately compute the stationary (normalized) wealth distribution. Finally, we also simulate an economy with $10^{5}$ agents. Figure 4 shows the results.

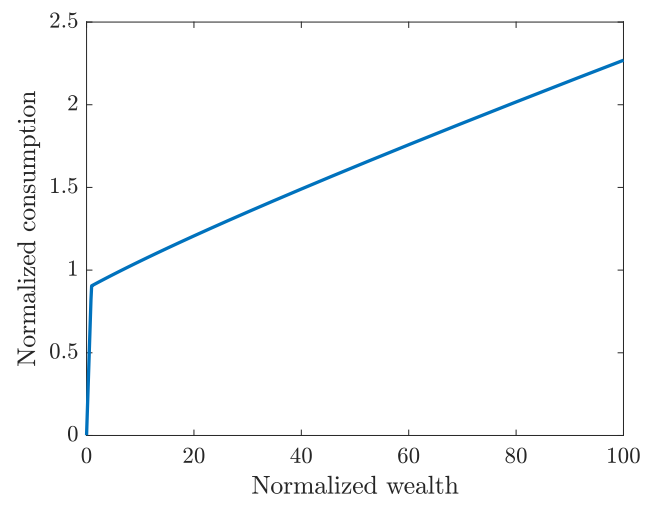

(a) Normalized consumption function.

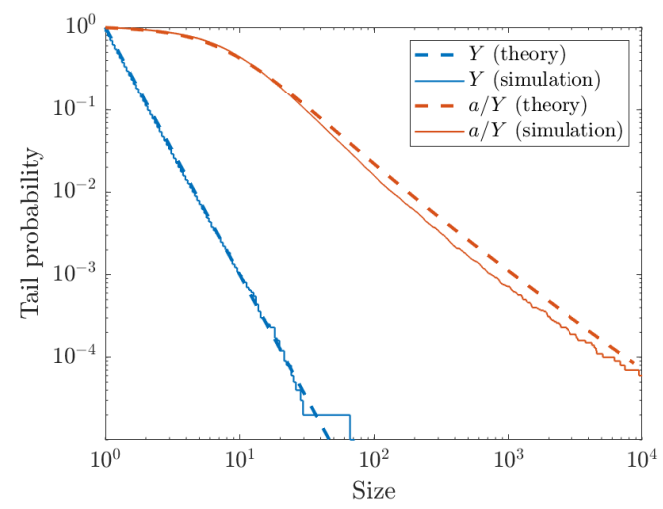

(b) Income and wealth distributions.

Figure 4: Solution to income fluctuation problem.

Figure 4a shows the normalized consumption function $\tilde{c}(\tilde{a})$ in the range $\tilde{a} \in$ $[0,100]$. Consistent with Proposition 3 , the consumption function is roughly linear for high asset level. Figure 4b shows the size distributions of income $Y$ normalized wealth $\tilde{a}=a / Y$ in a $\log -\log$ plot, both from the theoretical model and the simulation. The fact that the tail probability $\mathrm{P}(X>x)$ exhibits a straight line pattern in a log-log plot suggests that the size distributions have Pareto upper tails, consistent with theory. Furthermore, the slope for income is steeper than that of normalized wealth, so wealth (hence capital income) is more unequally distributed than labor income.

Finally, Figure 5 shows the income and wealth Pareto exponents when we change the income growth rate $g$ in the range $g \in[0.02,0.1]$, fixing other parameters. Because the income Pareto exponent is inversely proportional to income 
growth by (4.9), the labor income Pareto exponent is highly sensitive to income growth. On the other hand, the wealth (capital income) Pareto exponent does not depend much on income growth by the same intuition as in Example 1. Thus our model is consistent with our empirical findings in Section 3.2 that capital and labor income Pareto exponents are only weakly related.

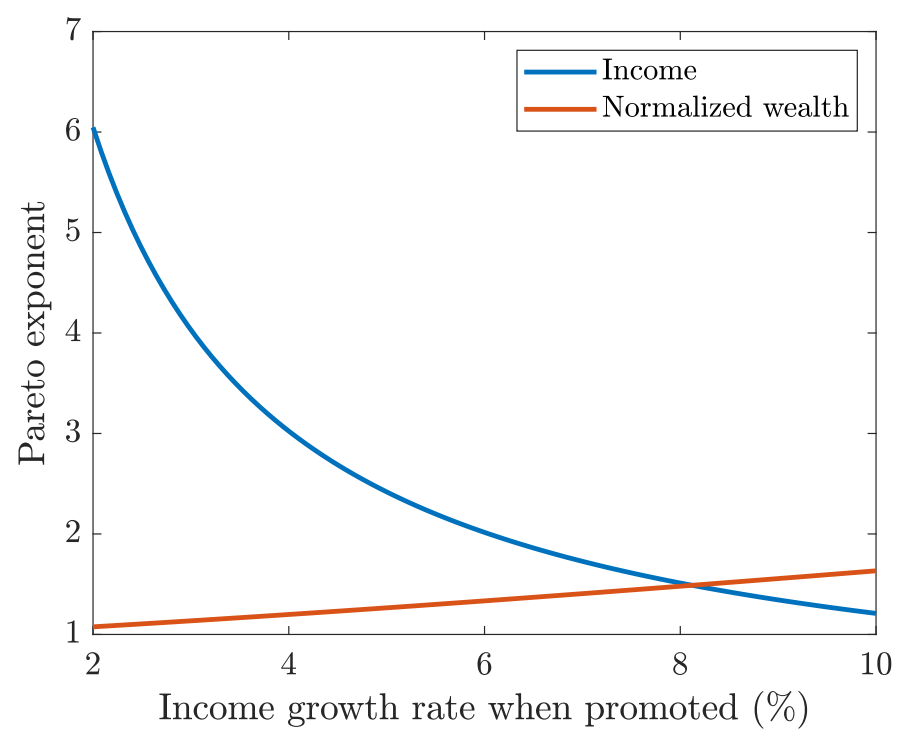

Figure 5: Dependence of income and wealth Pareto exponents on $g$.

\section{References}

S. Rao Aiyagari. Uninsured idiosyncratic risk and aggregate saving. Quarterly Journal of Economics, 109(3):659-684, August 1994. doi:10.2307/2118417.

Anthony B. Atkinson. Comparing the distribution of top incomes across countries. Journal of the European Economic Association, 3(2-3):393-401, May 2005. doi:10.1162/jeea.2005.3.2-3.393.

Anthony B. Atkinson and Thomas Piketty, editors. Top Incomes over the Twentieth Century. Oxford University Press, New York, NY, 2007.

Anthony B. Atkinson and Thomas Piketty, editors. Top Incomes: A Global Perspective. Oxford University Press, New York, NY, 2010.

Anthony B. Atkinson, Thomas Piketty, and Emmanuel Saez. Top incomes in the long run of history. Journal of Economic Literature, 49(1):3-71, March 2011. doi:10.1257/jel.49.1.3. 
Alejandro Badel, Moira Daly, Mark Huggett, and Martin Nybom. Top earners: Cross-country facts. Federal Reserve Bank of St. Louis Review, 100(3):237-257, 2018. doi:10.20955/r.100.237-57.

Ripsy Bandourian, James B. McDonald, and Robert S. Turley. A comparison of parametric models of income distributions across countries and over time. Estadistíca, 55(164):135-152, 2003. URL https://ssrn. com/abstract=324900.

Brendan K. Beare and Alexis Akira Toda. Geometrically stopped Markovian random growth processes and Pareto tails. 2017. URL https://arxiv.org/ $\mathrm{abs} / 1712.01431$.

Erik Bengtsson and Daniel Waldenström. Capital shares and income inequality: Evidence from the long run. Journal of Economic History, 78(3):712-743, September 2018. doi:10.1017/S0022050718000347.

Jess Benhabib, Alberto Bisin, and Mi Luo. Earnings inequality and other determinants of wealth inequality. American Economic Review: Papers and Proceedings, 107(5):593-597, May 2017. doi:10.1257/aer.p20171005.

Nicholas H. Bingham, Charles M. Goldie, and Jozef L. Teugels. Regular Variation, volume 27 of Encyclopedia of Mathematics and Its Applications. Cambridge University Press, 1987.

Richard V. Burkhauser, Shuaizhang Feng, Stephen P. Jenkins, and Jeff Larrimore. Recent trends in top income shares in the United States: Reconciling estimates from March CPS and IRS tax return data. Review of Economics and Statistics, 94(2):371-388, May 2012. doi:10.1162/REST_a_00200.

Christopher D. Carroll. Theoretical foundations of buffer stock saving. Quantitative Economics, 2020. URL http://qeconomics.org/ojs/forth/354/ 354-15.pdf. Forthcoming.

Christopher D. Carroll and Miles S. Kimball. On the concavity of the consumption function. Econometrica, 64(4):981-992, July 1996. doi:10.2307/2171853.

Gary Chamberlain and Charles A. Wilson. Optimal intertemporal consumption under uncertainty. Review of Economic Dynamics, 3(3):365-395, July 2000. doi:10.1006/redy.2000.0098. 
Jón Daníelsson and Casper G. de Vries. Tail index and quantile estimation with very high frequency data. Journal of Empirical Finance, 4(2-3):241-257, June 1997. doi:10.1016/S0927-5398(97)00008-X.

Jon Danielsson, Laurens de Haan, Liang Peng, and Casper G. de Vries. Using a bootstrap method to choose the sample fraction in tail index estimation. Journal of Multivariate Analysis, 76(2):226-248, February 2001. doi:10.1006/jmva.2000.1903.

Jon Danielsson, Lerby M. Ergun, Laurens de Haan, and Casper G. de Vries. Tail index estimation: Quantile driven threshold selection. 2016. URL https: //ssrn . com/abstract $=2717478$.

Paul Embrechts, Claudia Klüppelberg, and Thomas Mikosch. Modelling Extremal Events: For Insurance and Finance, volume 33. Springer Science \& Business Media, 2013.

Igor Fedotenkov. A review of more than one hundred Pareto-tail index estimators. Statistica, 80(3):245-299, 2020. doi:10.6092/issn.1973-2201/9533.

Xavier Gabaix. Power laws in economics and finance. Annual Review of Economics, 1:255-293, 2009. doi:10.1146/annurev.economics.050708.142940.

Xavier Gabaix. Power laws in economics: An introduction. Journal of Economic Perspectives, 30(1):185-206, Winter 2016. doi:10.1257/jep.30.1.185.

Xavier Gabaix and Rustam Ibragimov. Rank-1/2: A simple way to improve the OLS estimation of tail exponents. Journal of Business and Economic Statistics, 29(1):24-39, January 2011. doi:10.1198/jbes.2009.06157.

M. Ivette Gomes and Armelle Guillou. Extreme value theory and statistics of univariate extremes: A review. International Statistical Review, 83(2):263-292, August 2015. doi:10.1111/insr.12058.

Émilien Gouin-Bonenfant and Alexis Akira Toda. Pareto extrapolation: An analytical framework for studying tail inequality. 2018. URL https://ssrn.com/ abstract $=3260899$.

Peter Hall. On some simple estimates of an exponent of regular variation. Journal of the Royal Statistical Society, Series B, 44(1):37-42, September 1982. doi:10.1111/j.2517-6161.1982.tb01183.x. 
Peter Hall. Using the bootstrap to estimate mean squared error and select smoothing parameter in nonparametric problems. Journal of Multivariate Analysis, 32 (2):177-203, February 1990. doi:10.1016/0047-259X(90)90080-2.

Bruce M. Hill. A simple general approach to inference about the tail of a distribution. Annals of Statistics, 3(5):1163-1174, September 1975. doi:10.1214/aos/1176343247.

Yannick Hoga. Detecting tail risk differences in multivariate time series. Journal of Time Series Analysis, 39(5):665-689, March 2018. doi:10.1111/jtsa.12292.

Marat Ibragimov and Rustam Ibragimov. Heavy tails and upper-tail inequality: The case of Russia. Empirical Economics, 54(2):823-837, March 2018. doi:10.1007/s00181-017-1239-0.

Stephen P. Jenkins. Pareto models, top incomes and recent trends in UK income inequality. Economica, 84(334):261-289, April 2017. doi:10.1111/ecca.12217.

Anders Hedegaard Jessen and Thomas Mikosch. Regularly varying functions. Publications de l'Institut Mathématique, 80(94):171-192, 2006.

Harry Kesten. Random difference equations and renewal theory for products of random matrices. Acta Mathematica, 131(1):207-248, 1973. doi:10.1007/BF02392040.

Huiyu Li and John Stachurski. Solving the income fluctuation problem with unbounded rewards. Journal of Economic Dynamics and Control, 45:353-365, August 2014. doi:10.1016/j.jedc.2014.06.003.

Luxembourg Income Study (LIS) Database. http://www.lisdatacenter.org (multiple countries; September 2019-June 2021), 2021. Luxembourg: LIS.

Qingyin Ma and Alexis Akira Toda. A theory of the saving rate of the rich. Journal of Economic Theory, 192:105193, March 2021. doi:10.1016/j.jet.2021.105193.

Qingyin Ma, John Stachurski, and Alexis Akira Toda. The income fluctuation problem and the evolution of wealth. Journal of Economic Theory, 187:105003, May 2020. doi:10.1016/j.jet.2020.105003.

Mariusz Mirek. Heavy tail phenomenon and convergence to stable laws for iterated Lipschitz maps. Probability Theory and Related Fields, 151(3-4):705-734, December 2011. doi:10.1007/s00440-010-0312-9. 
Makoto Nirei and Wataru Souma. A two factor model of income distribution dynamics. Review of Income and Wealth, 53(3):440-459, September 2007. doi:10.1111/j.1475-4991.2007.00242.x.

Bogdan Oancea, Dan Pirjol, and Tudorel Andrei. A Pareto upper tail for capital income distribution. Physica A: Statistical Mechanics and its Applications, 492: 403-417, February 2018. doi:10.1016/j.physa.2017.09.034.

Vilfredo Pareto. La legge della demanda. Giornale degli Economisti, 10:59-68, January 1895.

Vilfredo Pareto. La Courbe de la Répartition de la Richesse. Imprimerie Ch. Viret-Genton, Lausanne, 1896.

Vilfredo Pareto. Cours d'Économie Politique, volume 2. F. Rouge, Lausanne, 1897.

Thomas Piketty. Income inequality in France, 1901-1998. Journal of Political Economy, 111(5):1004-1042, October 2003. doi:10.1086/376955.

Thomas Piketty and Emmanuel Saez. Income inequality in the United States, 1913-1998. Quarterly Journal of Economics, 118(1):1-41, February 2003. doi:10.1162/00335530360535135.

William J. Reed. The Pareto, Zipf and other power laws. Economics Letters, 74 (1):15-19, December 2001. doi:10.1016/S0165-1765(01)00524-9.

William J. Reed. The Pareto law of incomes - an explanation and an extension. Physica A, 319(1):469-486, March 2003. doi:10.1016/S0378-4371(02)01507-8.

William J. Reed and Murray Jorgensen. The double Pareto-lognormal distribution - a new parametric model for size distribution. Communications in Statistics-Theory and Methods, 33(8):1733-1753, 2004. doi:10.1081/STA120037438 .

Sidney Resnick and Cătălin Stărică. Smoothing the Hill estimator. Advances in Applied Probability, 29(1):271-293, March 1997. doi:10.2307/1427870.

Emmanuel Saez. Using elasticities to derive optimal income tax rates. Review of Economic Studies, 68(1):205-229, January 2001. doi:10.1111/1467-937X.00166. 
Emmanuel Saez and Stefanie Stantcheva. A simpler theory of optimal capital taxation. Journal of Public Economics, 162:120-142, June 2018. doi:10.1016/j.jpubeco.2017.10.004.

Aloysius Siow. Testing Becker's theory of positive assortative matching. Journal of Labor Economics, 33(2):409-441, April 2015. doi:10.1086/678496.

John Stachurski and Alexis Akira Toda. An impossibility theorem for wealth in heterogeneous-agent models with limited heterogeneity. Journal of Economic Theory, 182:1-24, July 2019. doi:10.1016/j.jet.2019.04.001.

John Stachurski and Alexis Akira Toda. Corrigendum to "An impossibility theorem for wealth in heterogeneous-agent models with limited heterogeneity" [Journal of Economic Theory 182 (2019) 1-24]. Journal of Economic Theory, 188: 105066, July 2020. doi:10.1016/j.jet.2020.105066.

Alexis Akira Toda. Income dynamics with a stationary double Pareto distribution. Physical Review E, 83(4):046122, 2011. doi:10.1103/PhysRevE.83.046122.

Alexis Akira Toda. The double power law in income distribution: Explanations and evidence. Journal of Economic Behavior and Organization, 84(1):364-381, September 2012. doi:10.1016/j.jebo.2012.04.012.

Alexis Akira Toda. Necessity of hyperbolic absolute risk aversion for the concavity of consumption functions. Journal of Mathematical Economics, 94:102460, May 2021. doi:10.1016/j.jmateco.2020.102460.

Alexis Akira Toda and Yulong Wang. Efficient minimum distance estimation of Pareto exponent from top income shares. Journal of Applied Econometrics, 36 (2):228-243, March 2021. doi:10.1002/jae.2788.

Philip Vermeulen. How fat is the top tail of the wealth distribution? Review of Income and Wealth, 64(2):357-387, June 2018. doi:10.1111/roiw.12279.

Herman O. A. Wold and Peter Whittle. A model explaining the Pareto distribution of wealth. Econometrica, 25(4):591-595, October 1957. doi:10.2307/1905385.

Menahem E. Yaari. Uncertain lifetime, life insurance, and the theory of the consumer. Review of Economic Studies, 32(2):137-150, April 1965. doi:10.2307/2296058. 


\section{A Proofs}

Proof of Proposition 1. Applying Theorem 2.2 of Ma et al. (2020) to the IID case, a sufficient condition for the existence of a solution to the detrended problem is $\mathrm{E}[\tilde{\beta}]<1$ and $\mathrm{E}[\tilde{\beta} \tilde{R}]<1$, which is equivalent to (4.4).

Proof of Proposition 3. The concavity of $\tilde{c}$ follows from Proposition 2.5 and Remark 2.1 of Ma et al. (2020). The asymptotic linearity of $\tilde{c}$ follows from Ma and Toda (2021, Theorem 3). Noting that

$$
\mathrm{E}\left[\tilde{\beta} \tilde{R}^{1-\gamma}\right]=\mathrm{E}\left[\beta G^{1-\gamma}(R / G)^{1-\gamma}\right]=\mathrm{E}\left[\beta R^{1-\gamma}\right]
$$

the limit (4.6) follows from their Example 2.

Proof of Proposition 4. Since by Proposition $3 \tilde{c}$ is concave, it is in particular Lipschitz continuous. Under the maintained assumptions, we can apply Theorem 1.8 of Mirek (2011) to deduce that the normalized wealth $\tilde{a}$ is either bounded or has a Pareto upper tail with exponent characterized as the solution to (4.7), where we have used the asymptotic linearity of $\tilde{c}$ established in Proposition 3.

By accounting, capital income (excluding capital loss) is

$$
Y_{\text {cap }}:=\max \{R-1,0\}(a-c(a))=\max \{R-1,0\} Y(\tilde{a}-\tilde{c}(\tilde{a})) .
$$

Using Proposition 3, this quantity is approximately equal to $\rho \max \{R-1,0\} Y \tilde{a}$. The claim $\alpha=\min \left\{\tilde{\alpha}, \alpha_{Y}\right\}$ then follows because asset return $R$ is thin-tailed and $a_{t}=Y_{t} \tilde{a}_{t}$ is the product of two (potentially dependent) random variables with Pareto upper tails, which inherits the smallest Pareto exponent by the result in Jessen and Mikosch (2006).

\section{B Solving the income fluctuation problem}

In this appendix we discuss how to solve the detrended income fluctuation problem. After detrending, the problem becomes

maximize

subject to

$$
\begin{aligned}
& \mathrm{E}_{0} \sum_{t=0}^{\infty}\left(\prod_{s=1}^{t} \beta_{t}\right) \frac{c_{t}^{1-\gamma}}{1-\gamma} \\
& a_{t+1}=R_{t+1}\left(a_{t}-c_{t}\right)+1, \\
& 0 \leq c_{t} \leq a_{t},
\end{aligned}
$$


where $\left\{R_{t}, \beta_{t}\right\}_{t=1}^{\infty}$ is IID (though $R_{t}$ and $\beta_{t}$ are generally correlated.) According to Ma et al. (2020), the Euler equation is

$$
c_{t}^{-\gamma}=\max \left\{\mathrm{E}_{t}\left[\beta_{t+1} R_{t+1} c_{t+1}^{-\gamma}\right], a_{t}^{-\gamma}\right\}
$$

Let $c(a)$ be the consumption function. Taking the $-1 / \gamma$-th power of (B.1), we obtain

$$
c(a)=\min \left\{\left(\mathrm{E}\left[\beta R c\left(a^{\prime}\right)^{-\gamma}\right]\right)^{-1 / \gamma}, a\right\},
$$

where $a^{\prime}=R(a-c(a))+1$. Therefore we can compute the consumption function using the following variant of the policy function iteration algorithm:

(i) Initialize the consumption function $c(a)$. For example, we can set $c(a)=$ $\min \{a, 1+m a\}$, where $m=\max \left\{1-\left(\mathrm{E}\left[\beta R^{1-\gamma}\right]\right)^{1 / \gamma}, 0\right\}$ is the theoretical asymptotic marginal propensity to consume according to (4.6).

(ii) Update $c(a)$ by the right-hand side of (B.2), where $a^{\prime}=R(a-c(a))+1$.

(iii) Iterate the above step until $c(a)$ converges.

While the above algorithm has no guarantee to converge unlike the "true" policy function iteration algorithm discussed in Ma et al. (2020), it has the advantage of avoiding root-finding and hence it is fast.

In Section 4, we use this algorithm on a 100-point exponential grid for normalized wealth $\tilde{a}$ that spans $\left[0,10^{4}\right]$, with a median grid point of 10 . The details on the exponential grid are discussed in Gouin-Bonenfant and Toda (2018).

\section{Tables (not for publication)}

\begin{tabular}{|c|c|c|c|c|c|c|c|c|c|}
\hline \multirow[b]{2}{*}{ Country } & \multirow[b]{2}{*}{ Year } & \multicolumn{4}{|c|}{ Labor income } & \multicolumn{4}{|c|}{ Capital income } \\
\hline & & $\widehat{\alpha}$ & s.e. & $k$ & $N$ & $\widehat{\alpha}$ & s.e. & $k$ & $N$ \\
\hline Australia & 1981 & 5.31 & 0.23 & 528 & 10568 & 2.1 & 0.1 & 474 & 9488 \\
\hline Australia & 1985 & 4.28 & 0.26 & 275 & 5492 & 1.41 & 0.09 & 262 & 5232 \\
\hline Australia & 1989 & 3.97 & 0.17 & 531 & 10629 & 1.47 & 0.06 & 549 & 10973 \\
\hline Australia & 1995 & 3.1 & 0.2 & 229 & 4574 & 1.71 & 0.13 & 168 & 3364 \\
\hline Australia & 2001 & 3.06 & 0.2 & 226 & 4510 & 1.47 & 0.12 & 155 & 3105 \\
\hline Australia & 2003 & 3.45 & 0.19 & 337 & 6741 & 1.52 & 0.1 & 224 & 4473 \\
\hline Australia & 2004 & 3.44 & 0.17 & 395 & 7893 & 1.42 & 0.08 & 307 & 6145 \\
\hline
\end{tabular}

Table 2: Point estimates of income Pareto exponents across countries and years. 
Table 2: Point estimates of income Pareto exponents across countries and years.

\begin{tabular}{|c|c|c|c|c|c|c|c|c|c|}
\hline \multirow[b]{2}{*}{ Country } & \multirow[b]{2}{*}{ Year } & \multicolumn{4}{|c|}{ Labor income } & \multicolumn{4}{|c|}{ Capital income } \\
\hline & & $\widehat{\alpha}$ & s.e. & $k$ & $N$ & $\widehat{\alpha}$ & s.e. & $k$ & $N$ \\
\hline Australia & 2008 & 3.07 & 0.17 & 333 & 6666 & 1.28 & 0.08 & 237 & 4749 \\
\hline Australia & 2010 & 3.39 & 0.15 & 547 & 10949 & 1.31 & 0.06 & 452 & 9030 \\
\hline Australia & 2014 & 3.15 & 0.14 & 489 & 9788 & 1.2 & 0.05 & 478 & 9569 \\
\hline Austria & 1994 & 3.38 & 0.32 & 109 & 2183 & 1.59 & 0.17 & 85 & 1693 \\
\hline Austria & 1997 & 3.59 & 0.36 & 100 & 1998 & 1.76 & 0.19 & 89 & 1787 \\
\hline Austria & 2000 & 3.17 & 0.36 & 79 & 1584 & 2.14 & 0.24 & 77 & 1547 \\
\hline Austria & 2004 & 3.35 & 0.25 & 187 & 3749 & 0.96 & 0.07 & 203 & 4064 \\
\hline Austria & 2007 & 3.24 & 0.23 & 205 & 4101 & 1.16 & 0.08 & 217 & 4334 \\
\hline Austria & 2010 & 3.52 & 0.24 & 216 & 4323 & 1 & 0.06 & 238 & 4752 \\
\hline Austria & 2013 & 3.37 & 0.24 & 201 & 4022 & 1.13 & 0.08 & 224 & 4471 \\
\hline Austria & 2016 & 3.35 & 0.23 & 204 & 4082 & 1.12 & 0.08 & 191 & 3823 \\
\hline Belgium & 1985 & 4.95 & 0.34 & 218 & 4357 & - & - & - & - \\
\hline Belgium & 1988 & 5.36 & 0.48 & 126 & 2518 & - & - & - & - \\
\hline Belgium & 1992 & 5.45 & 0.48 & 129 & 2581 & - & - & - & - \\
\hline Belgium & 1995 & 3.49 & 0.37 & 90 & 1790 & - & - & - & - \\
\hline Belgium & 1997 & 4.31 & 0.36 & 145 & 2906 & 1.62 & 0.11 & 206 & 4112 \\
\hline Belgium & 2000 & 3 & 0.35 & 72 & 1431 & - & - & - & - \\
\hline Belgium & 2003 & 3.79 & 0.3 & 164 & 3288 & 1.62 & 0.12 & 183 & 3664 \\
\hline Belgium & 2004 & 3.39 & 0.27 & 157 & 3135 & 1.42 & 0.11 & 159 & 3185 \\
\hline Belgium & 2005 & 3.69 & 0.27 & 189 & 3776 & 1.48 & 0.11 & 190 & 3799 \\
\hline Belgium & 2006 & 4.39 & 0.31 & 203 & 4069 & 1.39 & 0.09 & 220 & 4398 \\
\hline Belgium & 2007 & 3.36 & 0.24 & 202 & 4046 & 1.48 & 0.1 & 216 & 4328 \\
\hline Belgium & 2008 & 4.1 & 0.29 & 197 & 3944 & 1.44 & 0.1 & 197 & 3942 \\
\hline Belgium & 2009 & 4.47 & 0.32 & 196 & 3911 & 1.68 & 0.12 & 213 & 4259 \\
\hline Belgium & 2010 & 4.07 & 0.3 & 186 & 3723 & 1.61 & 0.11 & 204 & 4072 \\
\hline Belgium & 2011 & 3.95 & 0.29 & 181 & 3612 & 1.7 & 0.12 & 193 & 3859 \\
\hline Belgium & 2012 & 4.26 & 0.31 & 190 & 3793 & 1.62 & 0.11 & 205 & 4102 \\
\hline Belgium & 2013 & 4.22 & 0.31 & 183 & 3659 & 1.53 & 0.11 & 195 & 3908 \\
\hline Belgium & 2014 & 3.9 & 0.29 & 183 & 3663 & 1.64 & 0.12 & 192 & 3847 \\
\hline Belgium & 2015 & 4.24 & 0.32 & 178 & 3562 & 1.33 & 0.1 & 185 & 3695 \\
\hline Belgium & 2016 & 3.81 & 0.28 & 183 & 3669 & 1.8 & 0.13 & 185 & 3703 \\
\hline Belgium & 2017 & 4.22 & 0.32 & 179 & 3586 & 1.76 & 0.14 & 164 & 3276 \\
\hline Brazil & 2006 & 1.99 & 0.03 & 4978 & 99559 & 1.58 & 0.1 & 239 & 4780 \\
\hline Brazil & 2009 & 2.01 & 0.03 & 5000 & 100002 & 1.98 & 0.13 & 233 & 4667 \\
\hline Brazil & 2011 & 1.97 & 0.03 & 4453 & 89066 & 1.76 & 0.15 & 142 & 2845 \\
\hline Brazil & 2013 & 2.05 & 0.03 & 4583 & 91657 & 1.56 & 0.13 & 140 & 2804 \\
\hline Brazil & 2016 & 2.06 & 0.03 & 5756 & 115110 & 1.88 & 0.11 & 315 & 6296 \\
\hline Canada & 1971 & 3.9 & 0.12 & 1019 & 20386 & 1.66 & 0.07 & 498 & 9970 \\
\hline Canada & 1975 & 3.89 & 0.12 & 1088 & 21750 & 1.85 & 0.08 & 536 & 10717 \\
\hline Canada & 1981 & 4.51 & 0.18 & 617 & 12331 & 2.02 & 0.1 & 417 & 8342 \\
\hline Canada & 1987 & 4.49 & 0.22 & 433 & 8667 & 1.9 & 0.12 & 260 & 5190 \\
\hline
\end{tabular}


Table 2: Point estimates of income Pareto exponents across countries and years.

\begin{tabular}{|c|c|c|c|c|c|c|c|c|c|}
\hline \multirow[b]{2}{*}{ Country } & \multirow[b]{2}{*}{ Year } & \multicolumn{4}{|c|}{ Labor income } & \multicolumn{4}{|c|}{ Capital income } \\
\hline & & $\widehat{\alpha}$ & s.e. & $k$ & $N$ & $\widehat{\alpha}$ & s.e. & $k$ & $N$ \\
\hline Canada & 1991 & 4.39 & 0.16 & 763 & 15257 & 2 & 0.09 & 492 & 9847 \\
\hline Canada & 1994 & 4.18 & 0.11 & 1408 & 28155 & 1.76 & 0.07 & 704 & 14077 \\
\hline Canada & 1997 & 3.96 & 0.11 & 1251 & 25018 & 1.79 & 0.08 & 564 & 11273 \\
\hline Canada & 1998 & 3.5 & 0.1 & 1198 & 23969 & 1.47 & 0.06 & 674 & 13486 \\
\hline Canada & 2000 & 3.3 & 0.1 & 1115 & 22298 & 1.47 & 0.06 & 663 & 13264 \\
\hline Canada & 2004 & 3.34 & 0.1 & 1080 & 21594 & 1.56 & 0.06 & 593 & 11861 \\
\hline Canada & 2007 & 3.06 & 0.09 & 1046 & 20918 & 1.5 & 0.06 & 627 & 12533 \\
\hline Canada & 2010 & 3.36 & 0.11 & 975 & 19500 & 1.4 & 0.06 & 517 & 10341 \\
\hline Canada & 2012 & 3.52 & 0.11 & 953 & 19053 & 1.65 & 0.07 & 518 & 10370 \\
\hline Canada & 2013 & 3.84 & 0.13 & 903 & 18069 & 1.64 & 0.07 & 487 & 9741 \\
\hline Canada & 2014 & 3.41 & 0.11 & 924 & 18474 & 1.74 & 0.08 & 492 & 9836 \\
\hline Canada & 2015 & 3.42 & 0.11 & 989 & 19785 & 1.49 & 0.06 & 528 & 10552 \\
\hline Canada & 2016 & 3.47 & 0.11 & 1026 & 20526 & 1.64 & 0.07 & 532 & 10641 \\
\hline Canada & 2017 & 3.68 & 0.09 & 1516 & 30313 & 1.52 & 0.05 & 799 & 15982 \\
\hline Chile & 1990 & 1.95 & 0.06 & 1138 & 22755 & 1.62 & 0.21 & 62 & 1242 \\
\hline Chile & 1992 & 1.72 & 0.04 & 1597 & 31934 & 1.78 & 0.19 & 84 & 1678 \\
\hline Chile & 1994 & 1.99 & 0.04 & 1993 & 39851 & 1.91 & 0.19 & 104 & 2071 \\
\hline Chile & 1996 & 2.15 & 0.06 & 1509 & 30177 & 1.53 & 0.12 & 172 & 3437 \\
\hline Chile & 1998 & 1.99 & 0.04 & 2145 & 42903 & 1.64 & 0.13 & 167 & 3335 \\
\hline Chile & 2000 & 1.99 & 0.04 & 2886 & 57716 & 1.38 & 0.09 & 222 & 4432 \\
\hline Chile & 2003 & 1.89 & 0.03 & 3003 & 60055 & 1.48 & 0.1 & 232 & 4637 \\
\hline Chile & 2006 & 2.09 & 0.04 & 3256 & 65111 & 1.38 & 0.08 & 269 & 5374 \\
\hline Chile & 2009 & 2.18 & 0.04 & 2983 & 59668 & 1.48 & 0.11 & 181 & 3619 \\
\hline Chile & 2011 & 2.28 & 0.05 & 2544 & 50887 & 1.82 & 0.14 & 166 & 3312 \\
\hline Chile & 2013 & 2.21 & 0.04 & 2854 & 57079 & 1.76 & 0.13 & 182 & 3635 \\
\hline Chile & 2015 & 2.15 & 0.04 & 3574 & 71477 & 1.71 & 0.11 & 266 & 5314 \\
\hline Chile & 2017 & 2.18 & 0.04 & 2986 & 59724 & 1.56 & 0.1 & 241 & 4829 \\
\hline China & 2002 & 3.16 & 0.11 & 837 & 16745 & 1.72 & 0.17 & 108 & 2156 \\
\hline China & 2013 & 2.99 & 0.11 & 794 & 15878 & 2.06 & 0.09 & 505 & 10098 \\
\hline Colombia & 2004 & 2.13 & 0.1 & 413 & 8255 & 1.95 & 0.25 & 60 & 1196 \\
\hline Colombia & 2007 & 2.1 & 0.02 & 9734 & 194688 & 1.7 & 0.05 & 1189 & 23787 \\
\hline Colombia & 2010 & 2.24 & 0.02 & 9944 & 198885 & 1.63 & 0.05 & 1247 & 24944 \\
\hline Colombia & 2013 & 2.37 & 0.02 & 10039 & 200779 & 1.75 & 0.05 & 1283 & 25654 \\
\hline Colombia & 2016 & 2.45 & 0.02 & 10090 & 201793 & 1.64 & 0.05 & 1198 & 23957 \\
\hline Czech Rep. & 1992 & 3.84 & 0.15 & 664 & 13287 & - & - & - & - \\
\hline Czech Rep. & 1996 & 3.38 & 0.1 & 1179 & 23587 & 1.14 & 0.09 & 154 & 3077 \\
\hline Czech Rep. & 2002 & 3.31 & 0.19 & 304 & 6082 & - & - & - & - \\
\hline Czech Rep. & 2004 & 3.19 & 0.26 & 156 & 3125 & - & - & - & - \\
\hline Czech Rep. & 2007 & 3.49 & 0.17 & 413 & 8254 & 1.11 & 0.12 & 87 & 1735 \\
\hline Czech Rep. & 2010 & 3.74 & 0.21 & 328 & 6551 & 1.23 & 0.15 & 71 & 1422 \\
\hline Czech Rep. & 2013 & 3.45 & 0.2 & 300 & 5996 & 1.59 & 0.21 & 60 & 1198 \\
\hline
\end{tabular}


Table 2: Point estimates of income Pareto exponents across countries and years.

\begin{tabular}{|c|c|c|c|c|c|c|c|c|c|}
\hline \multirow[b]{2}{*}{ Country } & \multirow[b]{2}{*}{ Year } & \multicolumn{4}{|c|}{ Labor income } & \multicolumn{4}{|c|}{ Capital income } \\
\hline & & $\widehat{\alpha}$ & s.e. & $k$ & $N$ & $\widehat{\alpha}$ & s.e. & $k$ & $N$ \\
\hline Czech Rep. & 2016 & 3.97 & 0.22 & 326 & 6526 & 1.25 & 0.17 & 54 & 1083 \\
\hline Denmark & 2007 & 3.82 & 0.07 & 3063 & 61255 & 1.12 & 0.02 & 3938 & 78755 \\
\hline Denmark & 2010 & 3.37 & 0.06 & 2974 & 59488 & 1.14 & 0.02 & 3464 & 69287 \\
\hline Denmark & 2013 & 3.47 & 0.06 & 3044 & 60880 & 1.09 & 0.02 & 3404 & 68088 \\
\hline Denmark & 2016 & 3.42 & 0.06 & 3098 & 61970 & 1.23 & 0.02 & 2949 & 58989 \\
\hline Denmark & 1987 & 4.48 & 0.21 & 460 & 9199 & 1.53 & 0.06 & 579 & 11575 \\
\hline Denmark & 1992 & 4.59 & 0.21 & 458 & 9164 & 1.42 & 0.06 & 593 & 11853 \\
\hline Denmark & 1995 & 4.68 & 0.09 & 2865 & 57306 & 1.24 & 0.02 & 3510 & 70200 \\
\hline Dominican Rep. & 2000 & 4.26 & 0.08 & 2977 & 59549 & 1.18 & 0.02 & 3486 & 69714 \\
\hline Dominican Rep. & 2004 & 4.04 & 0.07 & 2991 & 59824 & 1.13 & 0.02 & 3394 & 67886 \\
\hline Dominican Rep. & 2007 & 2.12 & 0.11 & 374 & 7471 & - & - & - & - \\
\hline Egypt & 2012 & 1.97 & 0.09 & 505 & 10095 & - & - & - & - \\
\hline Estonia & 2000 & 3.06 & 0.19 & 260 & 5196 & - & - & - & - \\
\hline Estonia & 2004 & 3.23 & 0.26 & 156 & 3116 & - & - & - & - \\
\hline Estonia & 2007 & 4.12 & 0.28 & 210 & 4201 & 0.68 & 0.06 & 112 & 2250 \\
\hline Estonia & 2010 & 3.85 & 0.26 & 212 & 4241 & 0.91 & 0.09 & 97 & 1948 \\
\hline Estonia & 2013 & 3.44 & 0.22 & 248 & 4951 & 1.22 & 0.14 & 72 & 1450 \\
\hline Estonia & 2016 & 4.46 & 0.27 & 271 & 5422 & 1.05 & 0.13 & 62 & 1240 \\
\hline Finland & 1987 & 4.37 & 0.18 & 561 & 11225 & 1.45 & 0.07 & 395 & 7906 \\
\hline Finland & 1991 & 4.52 & 0.2 & 519 & 10380 & 1.43 & 0.07 & 417 & 8332 \\
\hline Finland & 1995 & 4.42 & 0.22 & 393 & 7867 & 1.25 & 0.09 & 212 & 4236 \\
\hline Finland & 2000 & 3.52 & 0.17 & 449 & 8977 & 1.1 & 0.06 & 296 & 5923 \\
\hline Finland & 2004 & 4.07 & 0.19 & 468 & 9368 & 1.02 & 0.05 & 403 & 8061 \\
\hline Finland & 2007 & 3.79 & 0.18 & 433 & 8664 & 1.01 & 0.05 & 425 & 8502 \\
\hline Finland & 2010 & 3.92 & 0.2 & 377 & 7537 & 1.06 & 0.05 & 379 & 7571 \\
\hline Finland & 2013 & 3.93 & 0.19 & 445 & 8899 & 1.04 & 0.05 & 457 & 9145 \\
\hline Finland & 2016 & 3.72 & 0.18 & 412 & 8237 & 1.19 & 0.06 & 416 & 8325 \\
\hline France & 1978 & 2.93 & 0.15 & 383 & 7664 & 1.75 & 0.21 & 71 & 1426 \\
\hline France & 1984 & 1.96 & 0.1 & 394 & 7875 & 1.75 & 0.18 & 99 & 1974 \\
\hline France & 1989 & 3.28 & 0.19 & 297 & 5942 & 1.68 & 0.18 & 84 & 1677 \\
\hline France & 1994 & 3.13 & 0.16 & 394 & 7880 & 1.68 & 0.08 & 437 & 8734 \\
\hline France & 2000 & 3.52 & 0.19 & 356 & 7112 & 1.58 & 0.08 & 426 & 8530 \\
\hline France & 2005 & 3.34 & 0.17 & 399 & 7987 & 1.51 & 0.07 & 416 & 8330 \\
\hline France & 2010 & 3.03 & 0.12 & 591 & 11818 & 1.49 & 0.06 & 583 & 11658 \\
\hline Germany & 1973 & 3.56 & 0.08 & 1881 & 37614 & 2.16 & 0.05 & 2245 & 44891 \\
\hline Germany & 1978 & 3.36 & 0.08 & 1787 & 35731 & 2.19 & 0.05 & 2233 & 44654 \\
\hline Germany & 1981 & 4.66 & 0.46 & 101 & 2024 & - & - & - & - \\
\hline Germany & 1983 & 4.54 & 0.11 & 1614 & 32288 & 2.26 & 0.05 & 2006 & 40130 \\
\hline Germany & 1984 & 3.97 & 0.27 & 212 & 4240 & 1.04 & 0.07 & 213 & 4259 \\
\hline Germany & 1987 & 4.24 & 0.31 & 193 & 3863 & 1.18 & 0.08 & 202 & 4050 \\
\hline Germany & 1989 & 3.31 & 0.24 & 187 & 3733 & 1.16 & 0.08 & 197 & 3940 \\
\hline
\end{tabular}


Table 2: Point estimates of income Pareto exponents across countries and years.

\begin{tabular}{|c|c|c|c|c|c|c|c|c|c|}
\hline \multirow[b]{2}{*}{ Country } & \multirow[b]{2}{*}{ Year } & \multicolumn{4}{|c|}{ Labor income } & \multicolumn{4}{|c|}{ Capital income } \\
\hline & & $\widehat{\alpha}$ & s.e. & $k$ & $N$ & $\widehat{\alpha}$ & s.e. & $k$ & $N$ \\
\hline Germany & 1991 & 4.79 & 0.29 & 272 & 5448 & 1.09 & 0.06 & 289 & 5789 \\
\hline Germany & 1994 & 4.54 & 0.28 & 269 & 5384 & 1.34 & 0.08 & 288 & 5758 \\
\hline Germany & 1995 & 4.66 & 0.29 & 264 & 5275 & 1.36 & 0.08 & 290 & 5802 \\
\hline Germany & 1998 & 4.56 & 0.27 & 277 & 5531 & 1.36 & 0.08 & 307 & 6136 \\
\hline Germany & 2000 & 3.92 & 0.19 & 439 & 8784 & 1.48 & 0.07 & 491 & 9829 \\
\hline Germany & 2001 & 3.46 & 0.16 & 464 & 9273 & 1.26 & 0.06 & 509 & 10174 \\
\hline Germany & 2002 & 3.57 & 0.17 & 442 & 8850 & 1.38 & 0.06 & 490 & 9798 \\
\hline Germany & 2003 & 3.64 & 0.18 & 430 & 8600 & 1.25 & 0.06 & 494 & 9875 \\
\hline Germany & 2004 & 3.67 & 0.18 & 415 & 8300 & 1.24 & 0.06 & 477 & 9544 \\
\hline Germany & 2005 & 3.31 & 0.16 & 443 & 8869 & 1.24 & 0.05 & 517 & 10338 \\
\hline Germany & 2006 & 3.29 & 0.16 & 414 & 8276 & 1.33 & 0.06 & 478 & 9562 \\
\hline Germany & 2007 & 3.45 & 0.18 & 389 & 7778 & 1.32 & 0.06 & 453 & 9055 \\
\hline Germany & 2008 & 3.24 & 0.17 & 365 & 7295 & 1.26 & 0.06 & 425 & 8497 \\
\hline Germany & 2009 & 3.43 & 0.15 & 531 & 10611 & 1.36 & 0.06 & 555 & 11102 \\
\hline Germany & 2010 & 3.45 & 0.14 & 626 & 12512 & 1.3 & 0.05 & 646 & 12913 \\
\hline Germany & 2011 & 3.3 & 0.13 & 615 & 12291 & 1.29 & 0.05 & 633 & 12664 \\
\hline Germany & 2012 & 3.4 & 0.13 & 696 & 13912 & 1.31 & 0.05 & 653 & 13051 \\
\hline Germany & 2013 & 3.4 & 0.14 & 610 & 12199 & 1.32 & 0.05 & 591 & 11824 \\
\hline Germany & 2014 & 3.85 & 0.16 & 610 & 12193 & 1.31 & 0.06 & 559 & 11176 \\
\hline Germany & 2015 & 3.13 & 0.13 & 550 & 11000 & 1.31 & 0.06 & 531 & 10625 \\
\hline Germany & 2016 & 3.43 & 0.14 & 611 & 12215 & 1.27 & 0.05 & 560 & 11203 \\
\hline Georgia & 2010 & 2.76 & 0.18 & 243 & 4867 & - & - & - & - \\
\hline Georgia & 2013 & 3.14 & 0.28 & 126 & 2512 & - & - & - & - \\
\hline Georgia & 2016 & 2.93 & 0.27 & 120 & 2390 & - & - & - & - \\
\hline Greece & 1995 & 3.68 & 0.28 & 169 & 3375 & 2.83 & 0.39 & 52 & 1033 \\
\hline Greece & 2000 & 3.56 & 0.31 & 129 & 2580 & - & - & - & - \\
\hline Greece & 2004 & 3.03 & 0.21 & 199 & 3987 & 2.12 & 0.3 & 50 & 1006 \\
\hline Greece & 2007 & 2.86 & 0.19 & 227 & 4533 & 2 & 0.25 & 63 & 1253 \\
\hline Greece & 2010 & 2.64 & 0.19 & 193 & 3858 & 2.12 & 0.28 & 58 & 1170 \\
\hline Greece & 2013 & 2.73 & 0.17 & 251 & 5015 & 2.24 & 0.26 & 76 & 1517 \\
\hline Greece & 2016 & 3.05 & 0.12 & 643 & 12867 & 2.43 & 0.19 & 165 & 3299 \\
\hline Guatemala & 2006 & 2.01 & 0.08 & 672 & 13448 & - & - & - & - \\
\hline Guatemala & 2011 & 2.2 & 0.09 & 631 & 12622 & - & - & - & - \\
\hline Guatemala & 2014 & 2.28 & 0.1 & 560 & 11203 & - & - & - & - \\
\hline Hungary & 1991 & 3.23 & 0.35 & 85 & 1693 & - & - & - & - \\
\hline Hungary & 1994 & 3.34 & 0.38 & 77 & 1532 & - & - & - & - \\
\hline Hungary & 1999 & 3.04 & 0.35 & 77 & 1531 & - & - & - & - \\
\hline Hungary & 2005 & 3.41 & 0.41 & 69 & 1384 & - & - & - & - \\
\hline Hungary & 2007 & 3.29 & 0.4 & 66 & 1328 & - & - & - & - \\
\hline Hungary & 2009 & 3.59 & 0.46 & 62 & 1250 & - & - & - & - \\
\hline Hungary & 2012 & 2.91 & 0.36 & 67 & 1343 & - & - & - & - \\
\hline
\end{tabular}


Table 2: Point estimates of income Pareto exponents across countries and years.

\begin{tabular}{|c|c|c|c|c|c|c|c|c|c|}
\hline \multirow[b]{2}{*}{ Country } & \multirow[b]{2}{*}{ Year } & \multicolumn{4}{|c|}{ Labor income } & \multicolumn{4}{|c|}{ Capital income } \\
\hline & & $\widehat{\alpha}$ & s.e. & $k$ & $N$ & $\widehat{\alpha}$ & s.e. & $k$ & $N$ \\
\hline Hungary & 2015 & 3.18 & 0.33 & 90 & 1809 & - & - & - & - \\
\hline Iceland & 2004 & 4.76 & 0.41 & 132 & 2632 & 1.17 & 0.12 & 92 & 1836 \\
\hline Iceland & 2007 & 4.34 & 0.38 & 129 & 2583 & 1.17 & 0.11 & 106 & 2112 \\
\hline Iceland & 2010 & 4.54 & 0.39 & 134 & 2675 & 1.14 & 0.09 & 150 & 2994 \\
\hline India & 2004 & 2.35 & 0.05 & 1992 & 39832 & 2.47 & 0.25 & 94 & 1874 \\
\hline India & 2011 & 2.12 & 0.05 & 1998 & 39958 & 1.66 & 0.17 & 101 & 2011 \\
\hline Ireland & 1987 & 3.46 & 0.31 & 124 & 2482 & 1.33 & 0.13 & 100 & 1998 \\
\hline Ireland & 1994 & 2.93 & 0.27 & 121 & 2426 & 1.33 & 0.18 & 56 & 1113 \\
\hline Ireland & 1995 & 2.65 & 0.26 & 107 & 2146 & 1.34 & 0.19 & 51 & 1025 \\
\hline Ireland & 1996 & 2.95 & 0.29 & 101 & 2021 & 1.56 & 0.22 & 51 & 1022 \\
\hline Ireland & 2000 & 3.23 & 0.33 & 95 & 1893 & 1.95 & 0.27 & 51 & 1017 \\
\hline Ireland & 2002 & 3.96 & 0.4 & 100 & 2000 & - & - & - & - \\
\hline Ireland & 2003 & 3.03 & 0.23 & 174 & 3471 & - & - & - & - \\
\hline Ireland & 2004 & 3 & 0.22 & 187 & 3731 & - & - & - & - \\
\hline Ireland & 2005 & 2.62 & 0.2 & 176 & 3522 & 1.83 & 0.25 & 52 & 1049 \\
\hline Ireland & 2006 & 2.49 & 0.19 & 171 & 3411 & 1.49 & 0.15 & 99 & 1984 \\
\hline Ireland & 2007 & 2.91 & 0.23 & 157 & 3143 & 1.48 & 0.17 & 75 & 1500 \\
\hline Ireland & 2008 & 2.73 & 0.22 & 153 & 3069 & - & - & - & - \\
\hline Ireland & 2009 & 3.27 & 0.28 & 134 & 2675 & - & - & - & - \\
\hline Ireland & 2010 & 3.38 & 0.3 & 126 & 2520 & - & - & - & - \\
\hline Ireland & 2011 & 3.78 & 0.32 & 136 & 2720 & - & - & - & - \\
\hline Ireland & 2012 & 3.35 & 0.28 & 145 & 2894 & - & - & - & - \\
\hline Ireland & 2013 & 3.2 & 0.25 & 164 & 3288 & - & - & - & - \\
\hline Ireland & 2014 & 3.06 & 0.24 & 164 & 3285 & - & - & - & - \\
\hline Ireland & 2015 & 2.91 & 0.23 & 158 & 3159 & - & - & - & - \\
\hline Ireland & 2016 & 2.76 & 0.22 & 161 & 3214 & - & - & - & - \\
\hline Ireland & 2017 & 2.46 & 0.21 & 142 & 2835 & - & - & - & - \\
\hline Israel & 1979 & 3.95 & 0.4 & 97 & 1941 & - & - & - & - \\
\hline Israel & 1986 & 3.25 & 0.23 & 197 & 3942 & - & - & - & - \\
\hline Israel & 1992 & 3.75 & 0.26 & 203 & 4057 & - & - & - & - \\
\hline Israel & 1997 & 3.01 & 0.21 & 204 & 4072 & - & - & - & - \\
\hline Israel & 2001 & 3.13 & 0.21 & 219 & 4382 & - & - & - & - \\
\hline Israel & 2002 & 3 & 0.2 & 227 & 4543 & - & - & - & - \\
\hline Israel & 2003 & 3.27 & 0.21 & 232 & 4639 & - & - & - & - \\
\hline Israel & 2004 & 3.75 & 0.25 & 228 & 4569 & - & - & - & - \\
\hline Israel & 2005 & 3.62 & 0.23 & 238 & 4752 & 1.29 & 0.15 & 74 & 1475 \\
\hline Israel & 2006 & 3.7 & 0.24 & 239 & 4780 & 1.38 & 0.17 & 63 & 1254 \\
\hline Israel & 2007 & 3.46 & 0.23 & 234 & 4682 & - & - & - & - \\
\hline Israel & 2008 & 3.05 & 0.2 & 230 & 4594 & - & - & - & - \\
\hline Israel & 2009 & 3.49 & 0.23 & 240 & 4792 & - & - & - & - \\
\hline Israel & 2010 & 2.96 & 0.19 & 237 & 4747 & - & - & - & - \\
\hline
\end{tabular}


Table 2: Point estimates of income Pareto exponents across countries and years.

\begin{tabular}{|c|c|c|c|c|c|c|c|c|c|}
\hline \multirow[b]{2}{*}{ Country } & \multirow[b]{2}{*}{ Year } & \multicolumn{4}{|c|}{ Labor income } & \multicolumn{4}{|c|}{ Capital income } \\
\hline & & $\widehat{\alpha}$ & s.e. & $k$ & $N$ & $\widehat{\alpha}$ & s.e. & $k$ & $N$ \\
\hline Israel & 2011 & 3.46 & 0.23 & 234 & 4683 & - & - & - & - \\
\hline Israel & 2012 & 3.54 & 0.19 & 343 & 6854 & 1.33 & 0.16 & 65 & 1305 \\
\hline Israel & 2013 & 3.27 & 0.17 & 372 & 7438 & 1.25 & 0.15 & 73 & 1451 \\
\hline Israel & 2014 & 3.24 & 0.18 & 330 & 6607 & 1.69 & 0.21 & 66 & 1330 \\
\hline Israel & 2015 & 3.46 & 0.19 & 341 & 6818 & 1.38 & 0.17 & 65 & 1301 \\
\hline Israel & 2016 & 3.45 & 0.18 & 348 & 6968 & 2.16 & 0.28 & 61 & 1215 \\
\hline Israel & 2017 & 3.6 & 0.19 & 358 & 7150 & 1.61 & 0.21 & 59 & 1173 \\
\hline Israel & 2018 & 3.38 & 0.18 & 347 & 6944 & 1.59 & 0.2 & 64 & 1271 \\
\hline Italy & 1986 & 3.5 & 0.2 & 301 & 6016 & 1.85 & 0.14 & 174 & 3474 \\
\hline Italy & 1987 & 3.55 & 0.2 & 302 & 6045 & 1.61 & 0.09 & 342 & 6844 \\
\hline Italy & 1989 & 4.15 & 0.24 & 308 & 6154 & 1.57 & 0.09 & 293 & 5865 \\
\hline Italy & 1991 & 4.43 & 0.26 & 291 & 5827 & 1.6 & 0.09 & 329 & 6587 \\
\hline Italy & 1993 & 3.76 & 0.23 & 272 & 5444 & 1.42 & 0.08 & 336 & 6724 \\
\hline Italy & 1995 & 3.24 & 0.2 & 274 & 5487 & 1.52 & 0.08 & 341 & 6811 \\
\hline Italy & 1998 & 3.37 & 0.22 & 244 & 4876 & 1.49 & 0.08 & 310 & 6191 \\
\hline Italy & 2000 & 3.1 & 0.19 & 264 & 5279 & 1.29 & 0.07 & 326 & 6516 \\
\hline Italy & 2004 & 2.39 & 0.15 & 246 & 4913 & 1.31 & 0.07 & 332 & 6641 \\
\hline Italy & 2008 & 3.19 & 0.21 & 239 & 4778 & 1.41 & 0.08 & 328 & 6552 \\
\hline Italy & 2010 & 3.35 & 0.22 & 236 & 4719 & 1.33 & 0.07 & 324 & 6490 \\
\hline Italy & 2014 & 2.76 & 0.19 & 220 & 4402 & 1.41 & 0.08 & 337 & 6748 \\
\hline Italy & 2016 & 2.69 & 0.19 & 193 & 3853 & 1.06 & 0.06 & 310 & 6197 \\
\hline Ivory Coast & 2002 & 1.83 & 0.08 & 491 & 9811 & - & - & - & - \\
\hline Ivory Coast & 2008 & 1.76 & 0.07 & 580 & 11594 & - & - & - & - \\
\hline Ivory Coast & 2015 & 1.9 & 0.08 & 565 & 11293 & - & - & - & - \\
\hline Japan & 2008 & 3.9 & 0.31 & 163 & 3256 & - & - & - & - \\
\hline Japan & 2010 & 4.4 & 0.39 & 127 & 2540 & - & - & - & - \\
\hline Japan & 2013 & 4.22 & 0.43 & 95 & 1891 & - & - & - & - \\
\hline Lithuania & 2009 & 3.42 & 0.24 & 201 & 4026 & - & - & - & - \\
\hline Lithuania & 2010 & 4.72 & 0.35 & 184 & 3680 & - & - & - & - \\
\hline Lithuania & 2011 & 4.36 & 0.31 & 198 & 3951 & - & - & - & - \\
\hline Lithuania & 2012 & 3.15 & 0.23 & 187 & 3746 & - & - & - & - \\
\hline Lithuania & 2013 & 3.61 & 0.26 & 190 & 3792 & - & - & - & - \\
\hline Lithuania & 2014 & 2.82 & 0.21 & 176 & 3510 & - & - & - & - \\
\hline Lithuania & 2015 & 3.13 & 0.24 & 176 & 3526 & - & - & - & - \\
\hline Lithuania & 2016 & 3.81 & 0.28 & 184 & 3683 & - & - & - & - \\
\hline Lithuania & 2017 & 3.25 & 0.24 & 188 & 3750 & - & - & - & - \\
\hline Luxembourg & 1985 & 6.01 & 0.68 & 78 & 1552 & - & - & - & - \\
\hline Luxembourg & 1991 & 5.1 & 0.58 & 77 & 1535 & - & - & - & - \\
\hline Luxembourg & 1994 & 4.75 & 0.58 & 68 & 1362 & - & - & - & - \\
\hline Luxembourg & 1997 & 5.23 & 0.54 & 95 & 1906 & - & - & - & - \\
\hline Luxembourg & 2000 & 4.37 & 0.46 & 92 & 1840 & - & - & - & - \\
\hline
\end{tabular}


Table 2: Point estimates of income Pareto exponents across countries and years.

\begin{tabular}{|c|c|c|c|c|c|c|c|c|c|}
\hline \multirow[b]{2}{*}{ Country } & \multirow[b]{2}{*}{ Year } & \multicolumn{4}{|c|}{ Labor income } & \multicolumn{4}{|c|}{ Capital income } \\
\hline & & $\widehat{\alpha}$ & s.e. & $k$ & $N$ & $\widehat{\alpha}$ & s.e. & $k$ & $N$ \\
\hline Luxembourg & 2004 & 4.09 & 0.35 & 138 & 2753 & - & - & - & - \\
\hline Luxembourg & 2007 & 3.02 & 0.25 & 151 & 3028 & 1.68 & 0.17 & 103 & 2066 \\
\hline Luxembourg & 2010 & 3.37 & 0.23 & 206 & 4111 & 1.71 & 0.13 & 175 & 3494 \\
\hline Luxembourg & 2013 & 3.59 & 0.3 & 141 & 2828 & 1.6 & 0.14 & 127 & 2534 \\
\hline Mexico & 1984 & 2.67 & 0.18 & 223 & 4461 & - & - & - & - \\
\hline Mexico & 1989 & 2.25 & 0.1 & 544 & 10876 & - & - & - & - \\
\hline Mexico & 1992 & 2.12 & 0.09 & 498 & 9959 & - & - & - & - \\
\hline Mexico & 1994 & 2.12 & 0.09 & 603 & 12068 & - & - & - & - \\
\hline Mexico & 1996 & 2.23 & 0.09 & 656 & 13128 & - & - & - & - \\
\hline Mexico & 1998 & 2.23 & 0.1 & 505 & 10092 & - & - & - & - \\
\hline Mexico & 2000 & 2.25 & 0.1 & 463 & 9262 & - & - & - & - \\
\hline Mexico & 2002 & 2.54 & 0.09 & 795 & 15905 & - & - & - & - \\
\hline Mexico & 2004 & 2.32 & 0.07 & 1046 & 20928 & 1.58 & 0.22 & 53 & 1055 \\
\hline Mexico & 2008 & 2.24 & 0.06 & 1359 & 27171 & 1.43 & 0.16 & 82 & 1635 \\
\hline Mexico & 2010 & 2.33 & 0.07 & 1252 & 25038 & 1.66 & 0.2 & 66 & 1323 \\
\hline Mexico & 2012 & 2.33 & 0.11 & 412 & 8247 & - & - & - & - \\
\hline Mexico & 2014 & 2.38 & 0.08 & 894 & 17887 & - & - & - & - \\
\hline Mexico & 2016 & 2.46 & 0.04 & 3227 & 64534 & 1.53 & 0.12 & 159 & 3186 \\
\hline Mexico & 2018 & 2.52 & 0.04 & 3406 & 68114 & 1.6 & 0.12 & 169 & 3389 \\
\hline Netherlands & 1983 & 5.16 & 0.42 & 154 & 3090 & - & - & - & - \\
\hline Netherlands & 1987 & 4.14 & 0.35 & 140 & 2792 & - & - & - & - \\
\hline Netherlands & 1990 & 3.79 & 0.31 & 149 & 2971 & 1.38 & 0.12 & 128 & 2570 \\
\hline Netherlands & 1993 & 4.3 & 0.32 & 178 & 3565 & 1.23 & 0.11 & 121 & 2423 \\
\hline Netherlands & 1999 & 4.34 & 0.35 & 153 & 3061 & 1.32 & 0.13 & 97 & 1942 \\
\hline Netherlands & 2004 & 3.43 & 0.18 & 358 & 7166 & 1.39 & 0.07 & 409 & 8171 \\
\hline Netherlands & 2007 & 3.17 & 0.16 & 401 & 8011 & 0.97 & 0.05 & 457 & 9136 \\
\hline Netherlands & 2010 & 3.65 & 0.18 & 400 & 8001 & 1.29 & 0.06 & 477 & 9539 \\
\hline Netherlands & 2013 & 3.62 & 0.18 & 390 & 7808 & 1.3 & 0.06 & 474 & 9486 \\
\hline Norway & 1979 & 1.73 & 0.08 & 414 & 8276 & 1.73 & 0.1 & 302 & 6048 \\
\hline Norway & 1986 & 5.05 & 0.35 & 213 & 4254 & 1.91 & 0.17 & 129 & 2588 \\
\hline Norway & 1991 & 3.83 & 0.2 & 368 & 7361 & 1.76 & 0.09 & 372 & 7448 \\
\hline Norway & 1995 & 3.46 & 0.17 & 401 & 8027 & 1.12 & 0.05 & 490 & 9800 \\
\hline Norway & 2000 & 3.19 & 0.13 & 574 & 11474 & 0.88 & 0.03 & 640 & 12804 \\
\hline Norway & 2004 & 3.98 & 0.17 & 547 & 10947 & 0.74 & 0.03 & 649 & 12979 \\
\hline Norway & 2007 & 3.74 & 0.04 & 8485 & 169708 & 1.09 & 0.01 & 10768 & 215363 \\
\hline Norway & 2010 & 3.55 & 0.04 & 8861 & 177229 & 0.88 & 0.01 & 11279 & 225584 \\
\hline Norway & 2013 & 3.35 & 0.04 & 9157 & 183146 & 0.85 & 0.01 & 11660 & 233192 \\
\hline Norway & 2016 & 3.45 & 0.04 & 9371 & 187424 & 0.72 & 0.01 & 11974 & 239485 \\
\hline Palestine & 2017 & 2.82 & 0.22 & 161 & 3214 & 1.43 & 0.2 & 50 & 1000 \\
\hline Panama & 2007 & 2.17 & 0.09 & 579 & 11571 & - & - & - & - \\
\hline Panama & 2010 & 2.24 & 0.09 & 588 & 11754 & - & - & - & - \\
\hline
\end{tabular}


Table 2: Point estimates of income Pareto exponents across countries and years.

\begin{tabular}{|c|c|c|c|c|c|c|c|c|c|}
\hline \multirow[b]{2}{*}{ Country } & \multirow[b]{2}{*}{ Year } & \multicolumn{4}{|c|}{ Labor income } & \multicolumn{4}{|c|}{ Capital income } \\
\hline & & $\widehat{\alpha}$ & s.e. & $k$ & $N$ & $\widehat{\alpha}$ & s.e. & $k$ & $N$ \\
\hline Panama & 2013 & 2.22 & 0.1 & 528 & 10551 & - & - & - & - \\
\hline Panama & 2016 & 2.4 & 0.11 & 511 & 10229 & - & - & - & - \\
\hline Paraguay & 2000 & 1.87 & 0.1 & 384 & 7685 & - & - & - & - \\
\hline Paraguay & 2004 & 1.89 & 0.1 & 372 & 7434 & - & - & - & - \\
\hline Paraguay & 2007 & 1.66 & 0.11 & 226 & 4528 & - & - & - & - \\
\hline Paraguay & 2010 & 1.77 & 0.12 & 235 & 4697 & - & - & - & - \\
\hline Paraguay & 2013 & 2.04 & 0.13 & 254 & 5073 & - & - & - & - \\
\hline Paraguay & 2016 & 1.87 & 0.09 & 474 & 9470 & - & - & - & - \\
\hline Peru & 2004 & 2.28 & 0.08 & 864 & 17289 & 1.87 & 0.18 & 110 & 2193 \\
\hline Peru & 2007 & 2.29 & 0.07 & 1023 & 20464 & 1.68 & 0.15 & 129 & 2571 \\
\hline Peru & 2010 & 2.49 & 0.08 & 986 & 19720 & 1.68 & 0.13 & 157 & 3137 \\
\hline Peru & 2013 & 2.53 & 0.07 & 1384 & 27670 & 1.64 & 0.12 & 191 & 3827 \\
\hline Peru & 2016 & 2.63 & 0.07 & 1633 & 32651 & 1.87 & 0.12 & 232 & 4649 \\
\hline Poland & 1986 & 3.79 & 0.18 & 461 & 9213 & - & - & - & - \\
\hline Poland & 1992 & 3.55 & 0.21 & 297 & 5944 & - & - & - & - \\
\hline Poland & 1995 & 2.67 & 0.08 & 1055 & 21091 & - & - & - & - \\
\hline Poland & 1999 & 3.31 & 0.1 & 1211 & 24216 & - & - & - & - \\
\hline Poland & 2004 & 2.92 & 0.09 & 1178 & 23557 & - & - & - & - \\
\hline Poland & 2007 & 2.84 & 0.08 & 1394 & 27872 & - & - & - & - \\
\hline Poland & 2010 & 3.03 & 0.08 & 1382 & 27640 & - & - & - & - \\
\hline Poland & 2013 & 2.91 & 0.08 & 1324 & 26475 & - & - & - & - \\
\hline Poland & 2016 & 3.16 & 0.09 & 1299 & 25983 & - & - & - & - \\
\hline Romania & 1995 & 3.55 & 0.09 & 1576 & 31519 & - & - & - & - \\
\hline Romania & 1997 & 3.51 & 0.09 & 1606 & 32122 & - & - & - & - \\
\hline Russia & 2000 & 2.39 & 0.21 & 132 & 2631 & - & - & - & - \\
\hline Russia & 2004 & 2.91 & 0.25 & 135 & 2705 & - & - & - & - \\
\hline Russia & 2007 & 3.69 & 0.3 & 149 & 2986 & - & - & - & - \\
\hline Russia & 2010 & 3.21 & 0.2 & 251 & 5025 & - & - & - & - \\
\hline Russia & 2011 & 3.4 & 0.16 & 435 & 8697 & - & - & - & - \\
\hline Russia & 2013 & 3.38 & 0.08 & 1915 & 38297 & 1.67 & 0.11 & 218 & 4360 \\
\hline Russia & 2014 & 3.49 & 0.08 & 1922 & 38433 & 1.79 & 0.12 & 221 & 4412 \\
\hline Russia & 2015 & 3.65 & 0.07 & 2539 & 50779 & 1.65 & 0.1 & 288 & 5752 \\
\hline Russia & 2016 & 3.47 & 0.04 & 6739 & 134781 & 1.91 & 0.07 & 786 & 15716 \\
\hline Russia & 2017 & 3.71 & 0.07 & 2539 & 50774 & 2.42 & 0.14 & 284 & 5671 \\
\hline Serbia & 2006 & 3.74 & 0.28 & 175 & 3491 & - & - & - & - \\
\hline Serbia & 2010 & 3.84 & 0.3 & 164 & 3270 & - & - & - & - \\
\hline Serbia & 2013 & 2.48 & 0.2 & 160 & 3201 & - & - & - & - \\
\hline Serbia & 2016 & 3.42 & 0.23 & 228 & 4566 & - & - & - & - \\
\hline Slovakia & 1992 & 4.31 & 0.18 & 572 & 11439 & - & - & - & - \\
\hline Slovakia & 1996 & 4.65 & 0.18 & 659 & 13176 & - & - & - & - \\
\hline Slovakia & 2004 & 3.14 & 0.22 & 199 & 3988 & - & - & - & - \\
\hline
\end{tabular}


Table 2: Point estimates of income Pareto exponents across countries and years.

\begin{tabular}{|c|c|c|c|c|c|c|c|c|c|}
\hline \multirow[b]{2}{*}{ Country } & \multirow[b]{2}{*}{ Year } & \multicolumn{4}{|c|}{ Labor income } & \multicolumn{4}{|c|}{ Capital income } \\
\hline & & $\widehat{\alpha}$ & s.e. & $k$ & $N$ & $\widehat{\alpha}$ & s.e. & $k$ & $N$ \\
\hline Slovakia & 2007 & 4.24 & 0.28 & 227 & 4541 & - & - & - & - \\
\hline Slovakia & 2010 & 3.86 & 0.26 & 219 & 4373 & 0.98 & 0.14 & 51 & 1024 \\
\hline Slovakia & 2013 & 3.38 & 0.22 & 226 & 4520 & 0.84 & 0.1 & 64 & 1289 \\
\hline Slovakia & 2014 & 4.18 & 0.28 & 229 & 4576 & 1.4 & 0.18 & 64 & 1285 \\
\hline Slovakia & 2015 & 4.14 & 0.27 & 228 & 4557 & 0.97 & 0.12 & 66 & 1317 \\
\hline Slovakia & 2016 & 5.06 & 0.34 & 218 & 4367 & 0.87 & 0.12 & 57 & 1139 \\
\hline Slovakia & 2017 & 5.66 & 0.38 & 218 & 4368 & 0.96 & 0.13 & 55 & 1105 \\
\hline Slovakia & 2018 & 5.49 & 0.38 & 212 & 4246 & 0.69 & 0.09 & 54 & 1079 \\
\hline Slovenia & 1997 & 5.24 & 0.48 & 119 & 2378 & - & - & - & - \\
\hline Slovenia & 1999 & 4.91 & 0.37 & 175 & 3492 & - & - & - & - \\
\hline Slovenia & 2004 & 5.27 & 0.41 & 164 & 3275 & - & - & - & - \\
\hline Slovenia & 2007 & 4.78 & 0.38 & 161 & 3219 & - & - & - & - \\
\hline Slovenia & 2010 & 4.9 & 0.37 & 173 & 3468 & - & - & - & - \\
\hline Slovenia & 2012 & 4.99 & 0.39 & 163 & 3252 & 1.48 & 0.15 & 92 & 1841 \\
\hline Slovenia & 2015 & 5.07 & 0.39 & 170 & 3399 & 1.12 & 0.12 & 84 & 1673 \\
\hline South Africa & 2008 & 1.76 & 0.11 & 251 & 5011 & - & - & - & - \\
\hline South Africa & 2010 & 1.89 & 0.14 & 194 & 3878 & - & - & - & - \\
\hline South Africa & 2012 & 2.08 & 0.13 & 258 & 5150 & - & - & - & - \\
\hline South Africa & 2015 & 2.2 & 0.12 & 336 & 6715 & - & - & - & - \\
\hline South Africa & 2017 & 2.27 & 0.12 & 364 & 7281 & - & - & - & - \\
\hline South Korea & 2006 & 4.11 & 0.15 & 720 & 14390 & 1.69 & 0.11 & 218 & 4353 \\
\hline South Korea & 2008 & 3.91 & 0.16 & 627 & 12542 & 1.79 & 0.13 & 181 & 3616 \\
\hline South Korea & 2010 & 4.15 & 0.17 & 614 & 12276 & 1.62 & 0.13 & 150 & 3003 \\
\hline South Korea & 2012 & 4.09 & 0.17 & 596 & 11911 & 1.58 & 0.12 & 166 & 3329 \\
\hline South Korea & 2014 & 4.36 & 0.18 & 561 & 11216 & 1.39 & 0.1 & 176 & 3526 \\
\hline South Korea & 2016 & 3.67 & 0.16 & 511 & 10214 & 1.34 & 0.1 & 164 & 3282 \\
\hline Spain & 1980 & 3.86 & 0.12 & 983 & 19651 & 2.07 & 0.24 & 74 & 1470 \\
\hline Spain & 1985 & 3.76 & 0.32 & 135 & 2707 & - & - & - & - \\
\hline Spain & 1990 & 4.23 & 0.15 & 809 & 16178 & 1.58 & 0.11 & 202 & 4036 \\
\hline Spain & 1995 & 3.91 & 0.27 & 204 & 4088 & 1.6 & 0.15 & 112 & 2249 \\
\hline Spain & 2000 & 3.21 & 0.25 & 169 & 3379 & 1.09 & 0.08 & 210 & 4206 \\
\hline Spain & 2004 & 4.07 & 0.19 & 459 & 9175 & 1.32 & 0.09 & 222 & 4433 \\
\hline Spain & 2007 & 4.37 & 0.2 & 485 & 9701 & 1.44 & 0.09 & 266 & 5327 \\
\hline Spain & 2010 & 5.14 & 0.24 & 441 & 8822 & 1.83 & 0.15 & 152 & 3043 \\
\hline Spain & 2013 & 3.56 & 0.17 & 441 & 8823 & 1.7 & 0.09 & 334 & 6681 \\
\hline Spain & 2016 & 3.33 & 0.15 & 508 & 10165 & 1.52 & 0.08 & 373 & 7451 \\
\hline Sweden & 1967 & 3.16 & 0.2 & 246 & 4912 & - & - & - & - \\
\hline Sweden & 1975 & 3.93 & 0.18 & 477 & 9535 & 1.55 & 0.08 & 392 & 7845 \\
\hline Sweden & 1981 & 4.45 & 0.21 & 432 & 8635 & 2.47 & 0.14 & 305 & 6092 \\
\hline Sweden & 1987 & 4.57 & 0.22 & 433 & 8658 & 1.79 & 0.09 & 398 & 7953 \\
\hline Sweden & 1992 & 4.5 & 0.19 & 541 & 10824 & 1.96 & 0.08 & 561 & 11215 \\
\hline
\end{tabular}


Table 2: Point estimates of income Pareto exponents across countries and years.

\begin{tabular}{|c|c|c|c|c|c|c|c|c|c|}
\hline \multirow[b]{2}{*}{ Country } & \multirow[b]{2}{*}{ Year } & \multicolumn{4}{|c|}{ Labor income } & \multicolumn{4}{|c|}{ Capital income } \\
\hline & & $\widehat{\alpha}$ & s.e. & $k$ & $N$ & $\widehat{\alpha}$ & s.e. & $k$ & $N$ \\
\hline Sweden & 1995 & 3.98 & 0.16 & 583 & 11655 & 1.61 & 0.06 & 650 & 12993 \\
\hline Sweden & 2000 & 3.62 & 0.16 & 516 & 10319 & 1.23 & 0.05 & 564 & 11273 \\
\hline Sweden & 2005 & 3.16 & 0.13 & 598 & 11951 & 1.08 & 0.04 & 606 & 12120 \\
\hline Switzerland & 1982 & 2.16 & 0.13 & 278 & 5570 & 1.34 & 0.09 & 212 & 4233 \\
\hline Switzerland & 1992 & 3.56 & 0.24 & 224 & 4486 & 1.33 & 0.09 & 242 & 4846 \\
\hline Switzerland & 2000 & 3.53 & 0.28 & 157 & 3140 & 1.41 & 0.12 & 132 & 2646 \\
\hline Switzerland & 2002 & 3.84 & 0.31 & 154 & 3074 & 1.56 & 0.14 & 129 & 2578 \\
\hline Switzerland & 2004 & 4.32 & 0.37 & 135 & 2697 & 1.38 & 0.12 & 132 & 2648 \\
\hline Switzerland & 2006 & 3.11 & 0.19 & 266 & 5329 & 1.22 & 0.08 & 210 & 4206 \\
\hline Switzerland & 2007 & 2.8 & 0.17 & 271 & 5427 & 1.23 & 0.08 & 253 & 5057 \\
\hline Switzerland & 2008 & 3 & 0.18 & 291 & 5822 & 1.11 & 0.07 & 250 & 5004 \\
\hline Switzerland & 2009 & 2.95 & 0.17 & 290 & 5805 & 1.23 & 0.07 & 270 & 5396 \\
\hline Switzerland & 2010 & 2.92 & 0.17 & 288 & 5759 & 1.09 & 0.06 & 337 & 6749 \\
\hline Switzerland & 2011 & 3.21 & 0.19 & 286 & 5714 & 1.24 & 0.07 & 337 & 6746 \\
\hline Switzerland & 2012 & 3.33 & 0.2 & 274 & 5471 & 1.26 & 0.07 & 329 & 6586 \\
\hline Switzerland & 2013 & 3.48 & 0.22 & 255 & 5097 & 1.36 & 0.08 & 310 & 6190 \\
\hline Switzerland & 2014 & 3.12 & 0.19 & 284 & 5672 & 1.28 & 0.07 & 328 & 6562 \\
\hline Switzerland & 2015 & 3.18 & 0.18 & 297 & 5947 & & 0.07 & 340 & 6794 \\
\hline Switzerland & 2016 & 3.09 & 0.17 & 316 & 6310 & 1.38 & 0.07 & 353 & 7068 \\
\hline Switzerland & 2017 & 3.2 & 0.2 & 252 & 5048 & 1.37 & 0.08 & 278 & 5568 \\
\hline Taiwan & 1981 & 4.2 & 0.15 & 750 & 14997 & 1.53 & 0.07 & 532 & 10635 \\
\hline Taiwan & 1986 & 3.96 & 0.14 & 796 & 15911 & 1.35 & 0.05 & 643 & 12864 \\
\hline Taiwan & 1991 & 4.1 & 0.15 & 788 & 15756 & 1.41 & 0.05 & 749 & 14978 \\
\hline Taiwan & 1995 & 4.3 & 0.16 & 681 & 13619 & 1.76 & 0.07 & 709 & 14184 \\
\hline Taiwan & 1997 & 4.27 & 0.17 & 629 & 12572 & 1.78 & 0.07 & 666 & 13311 \\
\hline Taiwan & 2000 & 4.2 & 0.17 & 615 & 12301 & 1.75 & 0.07 & 670 & 13396 \\
\hline Taiwan & 2005 & 4.17 & 0.17 & 595 & 11903 & 1.77 & 0.07 & 656 & 13127 \\
\hline Taiwan & 2007 & 3.82 & 0.16 & 602 & 12042 & 1.69 & 0.07 & 664 & 13290 \\
\hline Taiwan & 2010 & 3.85 & 0.15 & 637 & 12748 & 1.7 & 0.06 & 714 & 14287 \\
\hline Taiwan & 2013 & 3.85 & 0.15 & 665 & 13300 & 1.56 & 0.06 & 781 & 15615 \\
\hline Taiwan & 2016 & 3.88 & 0.15 & 682 & 13648 & 1.59 & 0.06 & 822 & 16449 \\
\hline United Kingdom & 1969 & 3.92 & 0.23 & 283 & 5669 & 1.12 & 0.08 & 205 & 4102 \\
\hline United Kingdom & 1974 & 3.62 & 0.22 & 259 & 5181 & 1.35 & 0.1 & 177 & 3547 \\
\hline United Kingdom & 1979 & 4.93 & 0.31 & 247 & 4937 & 1.34 & 0.09 & 214 & 4280 \\
\hline United Kingdom & 1986 & 4.49 & 0.3 & 226 & 4515 & 1.67 & 0.11 & 247 & 4942 \\
\hline United Kingdom & 1991 & 3.58 & 0.24 & 222 & 4445 & 1.66 & 0.1 & 259 & 5174 \\
\hline United Kingdom & 1994 & 2.99 & 0.11 & 778 & 15567 & 1.49 & 0.05 & 905 & 18098 \\
\hline United Kingdom & 1995 & 3.1 & 0.11 & 789 & 15777 & 1.53 & 0.05 & 879 & 17586 \\
\hline United Kingdom & 1996 & 2.98 & 0.11 & 770 & 15401 & 1.52 & 0.05 & 843 & 16869 \\
\hline United Kingdom & 1997 & 2.82 & 0.1 & 728 & 14554 & 1.45 & 0.05 & 764 & 15287 \\
\hline United Kingdom & 1998 & 2.88 & 0.11 & 699 & 13980 & 1.44 & 0.05 & 762 & 15237 \\
\hline
\end{tabular}


Table 2: Point estimates of income Pareto exponents across countries and years.

\begin{tabular}{|c|c|c|c|c|c|c|c|c|c|}
\hline \multirow[b]{2}{*}{ Country } & \multirow[b]{2}{*}{ Year } & \multicolumn{4}{|c|}{ Labor income } & \multicolumn{4}{|c|}{ Capital income } \\
\hline & & $\widehat{\alpha}$ & s.e. & $k$ & $N$ & $\widehat{\alpha}$ & s.e. & $k$ & $N$ \\
\hline United Kingdom & 1999 & 2.6 & 0.09 & 764 & 15289 & 1.41 & 0.05 & 862 & 17241 \\
\hline United Kingdom & 2000 & 2.33 & 0.09 & 732 & 14636 & 1.42 & 0.05 & 799 & 15978 \\
\hline United Kingdom & 2001 & 2.47 & 0.09 & 794 & 15887 & 1.39 & 0.05 & 840 & 16804 \\
\hline United Kingdom & 2002 & 2.9 & 0.1 & 898 & 17957 & 1.32 & 0.04 & 944 & 18872 \\
\hline United Kingdom & 2003 & 2.89 & 0.1 & 886 & 17714 & 1.25 & 0.04 & 936 & 18728 \\
\hline United Kingdom & 2004 & 2.65 & 0.09 & 867 & 17337 & 1.25 & 0.04 & 927 & 18535 \\
\hline United Kingdom & 2005 & 2.71 & 0.09 & 872 & 17447 & 1.38 & 0.05 & 914 & 18276 \\
\hline United Kingdom & 2006 & 2.51 & 0.09 & 796 & 15913 & 1.39 & 0.05 & 837 & 16738 \\
\hline United Kingdom & 2007 & 2.98 & 0.11 & 766 & 15327 & 1.33 & 0.05 & 819 & 16371 \\
\hline United Kingdom & 2008 & 2.97 & 0.11 & 771 & 15411 & 1.32 & 0.05 & 586 & 11718 \\
\hline United Kingdom & 2009 & 2.78 & 0.1 & 760 & 15197 & & 0.06 & 526 & 10528 \\
\hline United Kingdom & 2010 & 3 & 0.11 & 766 & 15318 & 1.34 & 0.06 & 492 & 9839 \\
\hline United Kingdom & 2011 & 3.23 & 0.13 & 638 & 12768 & 1.4 & 0.07 & 391 & 7823 \\
\hline United Kingdom & 2012 & 2.93 & 0.12 & 609 & 12180 & 1.33 & 0.07 & 374 & 7479 \\
\hline United Kingdom & 2013 & 3.23 & 0.13 & 616 & 12322 & 1.5 & 0.08 & 386 & 7715 \\
\hline United Kingdom & 2014 & 3 & 0.12 & 600 & 12009 & 1.46 & 0.07 & 396 & 7922 \\
\hline United Kingdom & 2015 & 2.94 & 0.12 & 586 & 11724 & 1.48 & 0.08 & 383 & 7663 \\
\hline United Kingdom & 2016 & & & 595 & & & 0 & 367 & 7340 \\
\hline United Kingdom & 2017 & 3.19 & 0.13 & 581 & 11614 & 1.47 & 0.08 & 348 & 6965 \\
\hline United Kingdom & 2018 & 2.9 & 0.12 & 579 & 11580 & 1.59 & 0.08 & 353 & 7062 \\
\hline United States & 1974 & 3.81 & 0.18 & 468 & 9366 & 1.51 & 0.09 & 278 & 5558 \\
\hline United States & 1979 & 3.64 & 0.07 & 2639 & 52783 & 1.46 & 0.03 & 2237 & 44749 \\
\hline United States & 1986 & 3.47 & 0.07 & 2283 & 45660 & 1.65 & 0.04 & 1914 & 38274 \\
\hline United States & 1991 & 3.4 & 0.07 & 2310 & 46195 & 1.54 & 0.04 & 1944 & 38871 \\
\hline United States & 1992 & 3.2 & 0.07 & 2296 & 45921 & 1.49 & 0.03 & 1907 & 38137 \\
\hline United States & 1993 & 2.57 & 0.05 & 2211 & 44224 & 1.46 & 0.03 & 1863 & 37252 \\
\hline United States & 1994 & 2.48 & 0.05 & 2213 & 44261 & 1.45 & 0.03 & 1868 & 37355 \\
\hline United States & 1995 & 2.52 & 0.06 & 1948 & 38958 & 1.48 & 0.04 & 1604 & 32076 \\
\hline United States & 1996 & 2.47 & 0.06 & 1978 & 39567 & 1.51 & 0.04 & 1558 & 31165 \\
\hline United States & 1997 & 2.4 & 0.05 & 1991 & & 1.47 & 0.04 & 1546 & 30913 \\
\hline United States & 1998 & 2.47 & 0.06 & 2013 & 40267 & 1.46 & 0.04 & 1557 & 31144 \\
\hline United States & 1999 & 2.43 & 0.05 & 2044 & 40886 & 1.44 & 0.04 & 1566 & 31320 \\
\hline United States & 2000 & 2.38 & 0.04 & 3229 & 64575 & 1.4 & 0.03 & 2348 & 46961 \\
\hline United States & 2001 & 2.35 & 0.04 & 3216 & 64322 & 1.31 & 0.03 & 2308 & 46168 \\
\hline United States & 2002 & 2.49 & 0.04 & 3200 & 64000 & 1.35 & 0.03 & 2198 & 43963 \\
\hline United States & 2003 & 2.43 & 0.04 & 3147 & 62939 & 1.37 & 0.03 & 2170 & 43410 \\
\hline United States & 2004 & 2.45 & 0.04 & 3117 & 62334 & 1.33 & 0.03 & 2118 & 42354 \\
\hline United States & 2005 & 2.31 & 0.04 & 3095 & 61899 & 1.42 & 0.03 & 2081 & 41624 \\
\hline United States & 2006 & 2.38 & 0.04 & 3085 & 61707 & 1.46 & 0.03 & 2013 & 40264 \\
\hline United States & 2007 & 2.56 & 0.05 & 3100 & 62002 & 1.49 & 0.03 & 1966 & 39312 \\
\hline United States & 2008 & 2.48 & 0.04 & 3103 & 62055 & 1.33 & 0.03 & 2026 & 40523 \\
\hline
\end{tabular}


Table 2: Point estimates of income Pareto exponents across countries and years.

\begin{tabular}{|c|c|c|c|c|c|c|c|c|c|}
\hline \multirow[b]{2}{*}{ Country } & \multirow[b]{2}{*}{ Year } & \multicolumn{4}{|c|}{ Labor income } & \multicolumn{4}{|c|}{ Capital income } \\
\hline & & $\widehat{\alpha}$ & s.e. & $k$ & $N$ & $\widehat{\alpha}$ & s.e. & $k$ & $N$ \\
\hline United States & 2009 & 2.48 & 0.04 & 3064 & 61288 & 1.33 & 0.03 & 1922 & 38446 \\
\hline United States & 2010 & 2.62 & 0.05 & 2997 & 59932 & 1.41 & 0.03 & 1869 & 37383 \\
\hline United States & 2011 & 2.42 & 0.04 & 2946 & 58921 & 1.4 & 0.03 & 1836 & 36728 \\
\hline United States & 2012 & 2.47 & 0.05 & 2970 & 59404 & 1.56 & 0.04 & 1843 & 36865 \\
\hline United States & 2013 & 2.5 & 0.06 & 2036 & 40721 & 1.41 & 0.04 & 1225 & 24494 \\
\hline United States & 2014 & 2.41 & 0.04 & 2905 & 58099 & 1.41 & 0.03 & 2316 & 46312 \\
\hline United States & 2015 & 2.29 & 0.04 & 2726 & 54510 & 1.36 & 0.03 & 2213 & 44260 \\
\hline United States & 2016 & 2.28 & 0.04 & 2736 & 54727 & 1.42 & 0.03 & 2270 & 45401 \\
\hline United States & 2017 & 2.39 & 0.05 & 2641 & 52816 & 1.45 & 0.03 & 2255 & 45102 \\
\hline United States & 2018 & 2.41 & 0.05 & 2658 & 53170 & 1.34 & 0.03 & 2265 & 45307 \\
\hline Uruguay & 2004 & 2.31 & 0.09 & 684 & 13671 & 1.82 & 0.23 & 62 & 1241 \\
\hline Uruguay & 2007 & 2.44 & 0.06 & 1855 & 37097 & 1.53 & 0.11 & 212 & 4236 \\
\hline Uruguay & 2010 & 2.59 & 0.06 & 1771 & 35428 & 1.64 & 0.11 & 204 & 4085 \\
\hline Uruguay & 2013 & 3 & 0.07 & 1763 & 35264 & 1.8 & 0.14 & 175 & 3497 \\
\hline Uruguay & 2016 & 2.76 & 0.07 & 1674 & 33484 & 1.69 & 0.13 & 182 & 3632 \\
\hline Vietnam & 2011 & 2.77 & 0.13 & 464 & 9279 & 1.26 & 0.15 & 68 & 1362 \\
\hline Vietnam & 2013 & 2.97 & 0.14 & 464 & 9276 & 1.77 & 0.21 & 69 & 1384 \\
\hline
\end{tabular}

Note: $\widehat{\alpha}$ : point estimate of Pareto exponent; s.e.: standard error $(\widehat{\alpha}(k) / \sqrt{k}) ; k$ : the number of order statistics used for the Hill-estimator; $N$ : the number of positive labor (resp. capital) income observations. "-" indicates fewer than 1,000 positive observations so estimates are omitted.

Table 3: Hypothesis testing of $\widehat{\alpha}_{\text {lab }}=\widehat{\alpha}_{\text {cap }}$.

\begin{tabular}{lcllllrrr}
\hline Country & Year & $\widehat{\alpha}_{\text {lab }}$ & s.e. & $\widehat{\alpha}_{\text {cap }}$ & s.e. & $k$ & $N$ & Reject $H_{0} ?$ \\
\hline Australia & 1981 & 5.26 & 0.24 & 2.1 & 0.1 & 474 & 9488 & Yes \\
Australia & 1985 & 4.22 & 0.26 & 1.4 & 0.09 & 262 & 5232 & Yes \\
Australia & 1989 & 3.95 & 0.17 & 1.46 & 0.06 & 531 & 10629 & Yes \\
Australia & 1995 & 2.91 & 0.22 & 1.7 & 0.13 & 168 & 3364 & Yes \\
Australia & 2001 & 3.24 & 0.26 & 1.45 & 0.12 & 155 & 3105 & Yes \\
Australia & 2003 & 3.25 & 0.22 & 1.51 & 0.1 & 224 & 4473 & Yes \\
Australia & 2004 & 3.38 & 0.19 & 1.41 & 0.08 & 307 & 6145 & Yes \\
Australia & 2008 & 3.3 & 0.21 & 1.27 & 0.08 & 237 & 4749 & Yes \\
Australia & 2010 & 3.31 & 0.16 & 1.29 & 0.06 & 455 & 9093 & Yes \\
Australia & 2014 & 3.14 & 0.14 & 1.19 & 0.05 & 481 & 9616 & Yes \\
Austria & 1994 & 3.12 & 0.34 & 1.59 & 0.17 & 85 & 1695 & Yes \\
Austria & 1997 & 3.55 & 0.37 & 1.78 & 0.19 & 90 & 1800 & No \\
Austria & 2000 & 3.1 & 0.35 & 2.1 & 0.24 & 79 & 1584 & No \\
Austria & 2004 & 3.34 & 0.24 & 0.99 & 0.07 & 188 & 3750 & Yes \\
Austria & 2007 & 3.23 & 0.23 & 1.17 & 0.08 & 205 & 4101 & Yes \\
Austria & 2010 & 3.51 & 0.24 & 1.05 & 0.07 & 216 & 4323 & Yes \\
\hline
\end{tabular}


Table 3: Hypothesis testing of $\widehat{\alpha}_{\text {lab }}=\widehat{\alpha}_{\text {cap }}$.

\begin{tabular}{|c|c|c|c|c|c|c|c|c|}
\hline Country & Year & $\widehat{\alpha}_{\text {lab }}$ & s.e. & $\widehat{\alpha}_{\text {cap }}$ & s.e. & $k$ & $N$ & Reject $H_{0}$ ? \\
\hline Austria & 2013 & 3.36 & 0.24 & 1.12 & 0.08 & 201 & 4022 & Yes \\
\hline Austria & 2016 & 3.31 & 0.24 & 1.11 & 0.08 & 192 & 3835 & Yes \\
\hline Belgium & 1997 & 4.25 & 0.35 & 1.82 & 0.15 & 145 & 2906 & Yes \\
\hline Belgium & 2003 & 3.79 & 0.29 & 1.6 & 0.12 & 173 & 3451 & Yes \\
\hline Belgium & 2004 & 3.38 & 0.27 & 1.41 & 0.11 & 159 & 3185 & Yes \\
\hline Belgium & 2005 & 3.68 & 0.27 & 1.47 & 0.11 & 189 & 3777 & Yes \\
\hline Belgium & 2006 & 4.38 & 0.31 & 1.5 & 0.11 & 203 & 4069 & Yes \\
\hline Belgium & 2007 & 3.35 & 0.24 & 1.48 & 0.1 & 202 & 4046 & Yes \\
\hline Belgium & 2008 & 4.1 & 0.29 & 1.44 & 0.1 & 197 & 3942 & Yes \\
\hline Belgium & 2009 & 4.46 & 0.32 & 1.75 & 0.12 & 196 & 3911 & Yes \\
\hline Belgium & 2010 & 4.05 & 0.3 & 1.7 & 0.12 & 186 & 3723 & Yes \\
\hline Belgium & 2011 & 3.91 & 0.29 & 1.6 & 0.12 & 181 & 3612 & Yes \\
\hline Belgium & 2012 & 4.25 & 0.31 & 1.69 & 0.12 & 190 & 3793 & Yes \\
\hline Belgium & 2013 & 4.18 & 0.31 & 1.64 & 0.12 & 183 & 3659 & Yes \\
\hline Belgium & 2014 & 3.89 & 0.29 & 1.73 & 0.13 & 183 & 3663 & Yes \\
\hline Belgium & 2015 & 4.24 & 0.32 & 1.3 & 0.1 & 178 & 3562 & Yes \\
\hline Belgium & 2016 & 3.77 & 0.28 & 1.81 & 0.13 & 183 & 3669 & Yes \\
\hline Belgium & 2017 & 4.19 & 0.33 & 1.72 & 0.13 & 164 & 3276 & Yes \\
\hline Brazil & 2006 & 3.32 & 0.21 & 1.53 & 0.1 & 240 & 4804 & No \\
\hline Brazil & 2009 & 3.19 & 0.21 & 1.98 & 0.13 & 236 & 4724 & No \\
\hline Brazil & 2011 & 2.89 & 0.24 & 1.7 & 0.14 & 145 & 2897 & No \\
\hline Brazil & 2013 & 2.94 & 0.25 & 1.48 & 0.12 & 143 & 2869 & Yes \\
\hline Brazil & 2016 & 3.39 & 0.19 & 1.88 & 0.11 & 315 & 6296 & Yes \\
\hline Canada & 1971 & 3.56 & 0.16 & 1.66 & 0.07 & 498 & 9970 & Yes \\
\hline Canada & 1975 & 4.02 & 0.17 & 1.84 & 0.08 & 536 & 10717 & Yes \\
\hline Canada & 1981 & 4.59 & 0.22 & 2.01 & 0.1 & 417 & 8342 & Yes \\
\hline Canada & 1987 & 4.78 & 0.3 & 1.88 & 0.12 & 260 & 5190 & Yes \\
\hline Canada & 1991 & 4.34 & 0.2 & 2 & 0.09 & 492 & 9847 & Yes \\
\hline Canada & 1994 & 4.07 & 0.15 & 1.75 & 0.07 & 704 & 14077 & Yes \\
\hline Canada & 1997 & 4.01 & 0.17 & 1.79 & 0.08 & 564 & 11273 & Yes \\
\hline Canada & 1998 & 3.22 & 0.12 & 1.46 & 0.06 & 674 & 13486 & Yes \\
\hline Canada & 2000 & 3.17 & 0.12 & 1.47 & 0.06 & 663 & 13264 & Yes \\
\hline Canada & 2004 & 3.15 & 0.13 & 1.56 & 0.06 & 593 & 11861 & Yes \\
\hline Canada & 2007 & 2.85 & 0.11 & 1.49 & 0.06 & 627 & 12533 & Yes \\
\hline Canada & 2010 & 3.06 & 0.13 & 1.4 & 0.06 & 517 & 10341 & Yes \\
\hline Canada & 2012 & 3.35 & 0.15 & 1.65 & 0.07 & 518 & 10370 & Yes \\
\hline Canada & 2013 & 3.93 & 0.18 & 1.56 & 0.07 & 487 & 9741 & Yes \\
\hline Canada & 2014 & 3.23 & 0.15 & 1.71 & 0.08 & 492 & 9836 & Yes \\
\hline Canada & 2015 & 3.33 & 0.15 & 1.49 & 0.06 & 528 & 10552 & Yes \\
\hline Canada & 2016 & 3.38 & 0.15 & 1.64 & 0.07 & 532 & 10641 & Yes \\
\hline Canada & 2017 & 3.53 & 0.12 & 1.51 & 0.05 & 799 & 15982 & Yes \\
\hline Chile & 1990 & 2.24 & 0.28 & 1.62 & 0.21 & 62 & 1242 & No \\
\hline
\end{tabular}


Table 3: Hypothesis testing of $\widehat{\alpha}_{\text {lab }}=\widehat{\alpha}_{\text {cap }}$.

\begin{tabular}{|c|c|c|c|c|c|c|c|c|}
\hline Country & Year & $\widehat{\alpha}_{\text {lab }}$ & s.e. & $\widehat{\alpha}_{\text {cap }}$ & s.e. & $k$ & $N$ & Reject $H_{0}$ ? \\
\hline Chile & 1992 & 3.42 & 0.37 & 1.76 & 0.19 & 84 & 1678 & Yes \\
\hline Chile & 1994 & 2.61 & 0.26 & 1.91 & 0.19 & 104 & 2071 & No \\
\hline Chile & 1996 & 2.71 & 0.21 & 1.52 & 0.12 & 172 & 3437 & Yes \\
\hline Chile & 1998 & 2.43 & 0.19 & 1.64 & 0.13 & 167 & 3335 & No \\
\hline Chile & 2000 & 2.28 & 0.15 & 1.38 & 0.09 & 222 & 4432 & Yes \\
\hline Chile & 2003 & 2.28 & 0.15 & 1.45 & 0.1 & 232 & 4637 & No \\
\hline Chile & 2006 & 2.31 & 0.14 & 1.38 & 0.08 & 269 & 5374 & Yes \\
\hline Chile & 2009 & 3.02 & 0.22 & 1.48 & 0.11 & 181 & 3619 & Yes \\
\hline Chile & 2011 & 3.48 & 0.27 & 1.82 & 0.14 & 166 & 3312 & Yes \\
\hline Chile & 2013 & 2.87 & 0.21 & 1.76 & 0.13 & 182 & 3635 & No \\
\hline Chile & 2015 & 3.27 & 0.2 & 1.71 & 0.11 & 266 & 5314 & Yes \\
\hline Chile & 2017 & 2.73 & 0.18 & 1.56 & 0.1 & 241 & 4829 & No \\
\hline China & 2002 & 4.24 & 0.41 & 1.72 & 0.17 & 108 & 2167 & Yes \\
\hline China & 2013 & 3.1 & 0.14 & 2.06 & 0.09 & 505 & 10098 & No \\
\hline Colombia & 2004 & 2.37 & 0.28 & 1.97 & 0.23 & 71 & 1411 & No \\
\hline Colombia & 2007 & 1.97 & 0.06 & 1.7 & 0.05 & 1189 & 23787 & No \\
\hline Colombia & 2010 & 2.52 & 0.07 & 1.63 & 0.05 & 1247 & 24944 & No \\
\hline Colombia & 2013 & 2.64 & 0.07 & 1.75 & 0.05 & 1283 & 25654 & Yes \\
\hline Colombia & 2016 & 2.55 & 0.07 & 1.64 & 0.05 & 1198 & 23957 & Yes \\
\hline Czech Rep & 1996 & 3 & 0.24 & 1.14 & 0.09 & 154 & 3077 & Yes \\
\hline Czech Rep & 2007 & 3.62 & 0.39 & 1.11 & 0.12 & 87 & 1735 & Yes \\
\hline Czech Rep & 2010 & 4.09 & 0.49 & 1.23 & 0.15 & 71 & 1422 & Yes \\
\hline Czech Rep & 2013 & 3.12 & 0.4 & 1.54 & 0.2 & 60 & 1198 & No \\
\hline Czech Rep & 2016 & 3.74 & 0.51 & 1.24 & 0.17 & 54 & 1083 & Yes \\
\hline Denmark & 2007 & 3.82 & 0.07 & 1.17 & 0.02 & 3063 & 61255 & Yes \\
\hline Denmark & 2010 & 3.37 & 0.06 & 1.2 & 0.02 & 2974 & 59488 & Yes \\
\hline Denmark & 2013 & 3.47 & 0.06 & 1.13 & 0.02 & 3044 & 60880 & Yes \\
\hline Denmark & 2016 & 3.41 & 0.06 & 1.23 & 0.02 & 2949 & 58989 & Yes \\
\hline Denmark & 1987 & 4.46 & 0.21 & 1.64 & 0.08 & 460 & 9199 & Yes \\
\hline Denmark & 1992 & 4.57 & 0.21 & 1.46 & 0.07 & 458 & 9164 & Yes \\
\hline Denmark & 1995 & 4.68 & 0.09 & 1.26 & 0.02 & 2865 & 57306 & Yes \\
\hline Dominican Rep. & 2000 & 4.26 & 0.08 & 1.19 & 0.02 & 2977 & 59549 & Yes \\
\hline Dominican Rep. & 2004 & 4.03 & 0.07 & 1.17 & 0.02 & 2991 & 59824 & Yes \\
\hline Estonia & 2007 & 4.53 & 0.43 & 0.67 & 0.06 & 112 & 2250 & Yes \\
\hline Estonia & 2010 & 4.68 & 0.48 & 0.91 & 0.09 & 97 & 1948 & Yes \\
\hline Estonia & 2013 & 3.65 & 0.42 & 1.16 & 0.13 & 77 & 1549 & Yes \\
\hline Estonia & 2016 & 6.68 & 0.85 & 1.05 & 0.13 & 62 & 1240 & Yes \\
\hline Finland & 1987 & 4.35 & 0.22 & 1.45 & 0.07 & 395 & 7906 & Yes \\
\hline Finland & 1991 & 4.48 & 0.22 & 1.43 & 0.07 & 417 & 8332 & Yes \\
\hline Finland & 1995 & 4.5 & 0.31 & 1.25 & 0.09 & 212 & 4236 & Yes \\
\hline Finland & 2000 & 3.53 & 0.21 & 1.09 & 0.06 & 296 & 5923 & Yes \\
\hline Finland & 2004 & 3.91 & 0.19 & 1.02 & 0.05 & 403 & 8061 & Yes \\
\hline
\end{tabular}


Table 3: Hypothesis testing of $\widehat{\alpha}_{\text {lab }}=\widehat{\alpha}_{\text {cap }}$.

\begin{tabular}{|c|c|c|c|c|c|c|c|c|}
\hline Country & Year & $\widehat{\alpha}_{\text {lab }}$ & s.e. & $\widehat{\alpha}_{\text {cap }}$ & s.e. & $k$ & $N$ & Reject $H_{0}$ ? \\
\hline Finland & 2007 & 3.82 & 0.19 & 1.01 & 0.05 & 425 & 8502 & Yes \\
\hline Finland & 2010 & 3.91 & 0.2 & 1.05 & 0.05 & 377 & 7537 & Yes \\
\hline Finland & 2013 & 3.9 & 0.19 & 1.04 & 0.05 & 445 & 8899 & Yes \\
\hline Finland & 2016 & 3.71 & 0.18 & 1.19 & 0.06 & 412 & 8237 & Yes \\
\hline France & 1978 & 2.4 & 0.28 & 1.75 & 0.21 & 71 & 1426 & No \\
\hline France & 1984 & 1.52 & 0.15 & 1.73 & 0.17 & 99 & 1974 & No \\
\hline France & 1989 & 3.43 & 0.37 & 1.65 & 0.18 & 84 & 1677 & Yes \\
\hline France & 1994 & 3.13 & 0.16 & 1.68 & 0.08 & 394 & 7880 & Yes \\
\hline France & 2000 & 3.51 & 0.19 & 1.72 & 0.09 & 356 & 7112 & Yes \\
\hline France & 2005 & 3.33 & 0.17 & 1.53 & 0.08 & 399 & 7987 & Yes \\
\hline France & 2010 & 3.01 & 0.12 & 1.49 & 0.06 & 583 & 11658 & Yes \\
\hline Germany & 1973 & 3.56 & 0.08 & 2.13 & 0.05 & 1881 & 37614 & No \\
\hline Germany & 1978 & 3.36 & 0.08 & 2.18 & 0.05 & 1787 & 35731 & No \\
\hline Germany & 1983 & 4.54 & 0.11 & 2.23 & 0.06 & 1614 & 32288 & Yes \\
\hline Germany & 1984 & 3.96 & 0.27 & 1.03 & 0.07 & 212 & 4240 & Yes \\
\hline Germany & 1987 & 4.23 & 0.3 & 1.17 & 0.08 & 193 & 3863 & Yes \\
\hline Germany & 1989 & 3.29 & 0.24 & 1.18 & 0.09 & 187 & 3733 & Yes \\
\hline Germany & 1991 & 4.77 & 0.29 & 1.1 & 0.07 & 272 & 5448 & Yes \\
\hline Germany & 1994 & 4.54 & 0.28 & 1.32 & 0.08 & 269 & 5384 & Yes \\
\hline Germany & 1995 & 4.65 & 0.29 & 1.33 & 0.08 & 264 & 5275 & Yes \\
\hline Germany & 1998 & 4.56 & 0.27 & 1.31 & 0.08 & 277 & 5531 & Yes \\
\hline Germany & 2000 & 3.91 & 0.19 & 1.51 & 0.07 & 439 & 8784 & Yes \\
\hline Germany & 2001 & 3.46 & 0.16 & 1.31 & 0.06 & 464 & 9273 & Yes \\
\hline Germany & 2002 & 3.57 & 0.17 & 1.35 & 0.06 & 442 & 8850 & Yes \\
\hline Germany & 2003 & 3.64 & 0.18 & 1.28 & 0.06 & 430 & 8600 & Yes \\
\hline Germany & 2004 & 3.67 & 0.18 & 1.29 & 0.06 & 415 & 8300 & Yes \\
\hline Germany & 2005 & 3.29 & 0.16 & 1.27 & 0.06 & 443 & 8869 & Yes \\
\hline Germany & 2006 & 3.28 & 0.16 & 1.32 & 0.06 & 414 & 8276 & Yes \\
\hline Germany & 2007 & 3.44 & 0.17 & 1.35 & 0.07 & 389 & 7778 & Yes \\
\hline Germany & 2008 & 3.22 & 0.17 & 1.29 & 0.07 & 365 & 7295 & Yes \\
\hline Germany & 2009 & 3.43 & 0.15 & 1.37 & 0.06 & 531 & 10611 & Yes \\
\hline Germany & 2010 & 3.44 & 0.14 & 1.29 & 0.05 & 626 & 12512 & Yes \\
\hline Germany & 2011 & 3.3 & 0.13 & 1.28 & 0.05 & 615 & 12291 & Yes \\
\hline Germany & 2012 & 3.43 & 0.13 & 1.31 & 0.05 & 653 & 13051 & Yes \\
\hline Germany & 2013 & 3.4 & 0.14 & 1.32 & 0.05 & 591 & 11824 & Yes \\
\hline Germany & 2014 & 3.78 & 0.16 & 1.3 & 0.06 & 559 & 11176 & Yes \\
\hline Germany & 2015 & 3.09 & 0.13 & 1.31 & 0.06 & 531 & 10625 & Yes \\
\hline Germany & 2016 & 3.48 & 0.15 & 1.27 & 0.05 & 560 & 11203 & Yes \\
\hline Greece & 1995 & 3.7 & 0.51 & 2.83 & 0.39 & 52 & 1033 & No \\
\hline Greece & 2004 & 3.64 & 0.52 & 2.12 & 0.3 & 50 & 1006 & No \\
\hline Greece & 2007 & 2.81 & 0.35 & 1.97 & 0.25 & 63 & 1253 & No \\
\hline Greece & 2010 & 3.01 & 0.39 & 2.09 & 0.27 & 58 & 1170 & No \\
\hline
\end{tabular}


Table 3: Hypothesis testing of $\widehat{\alpha}_{\text {lab }}=\widehat{\alpha}_{\text {cap }}$.

\begin{tabular}{|c|c|c|c|c|c|c|c|c|}
\hline Country & Year & $\widehat{\alpha}_{\text {lab }}$ & s.e. & $\widehat{\alpha}_{\text {cap }}$ & s.e. & $k$ & $N$ & Reject $H_{0}$ ? \\
\hline Greece & 2013 & 2.68 & 0.31 & 2.22 & 0.25 & 76 & 1517 & No \\
\hline Greece & 2016 & 2.72 & 0.21 & 2.46 & 0.19 & 174 & 3480 & No \\
\hline Iceland & 2004 & 4.71 & 0.49 & 1.15 & 0.12 & 92 & 1840 & Yes \\
\hline Iceland & 2007 & 4.4 & 0.43 & 1.16 & 0.11 & 106 & 2113 & Yes \\
\hline Iceland & 2010 & 4.51 & 0.39 & 1.13 & 0.1 & 134 & 2675 & Yes \\
\hline India & 2004 & 2.85 & 0.29 & 2.47 & 0.25 & 94 & 1876 & No \\
\hline India & 2011 & 2.21 & 0.22 & 1.43 & 0.14 & 101 & 2027 & No \\
\hline Ireland & 1987 & 3.41 & 0.34 & 1.29 & 0.13 & 100 & 1998 & Yes \\
\hline Ireland & 1994 & 2.54 & 0.34 & 1.26 & 0.17 & 56 & 1114 & Yes \\
\hline Ireland & 1995 & 2.31 & 0.32 & 1.3 & 0.18 & 51 & 1026 & Yes \\
\hline Ireland & 1996 & 2.68 & 0.38 & 1.56 & 0.22 & 51 & 1023 & No \\
\hline Ireland & 2000 & 3.44 & 0.41 & 1.7 & 0.2 & 69 & 1371 & Yes \\
\hline Ireland & 2005 & 1.94 & 0.27 & 1.8 & 0.25 & 52 & 1049 & No \\
\hline Ireland & 2006 & 2.23 & 0.22 & 1.48 & 0.15 & 99 & 1984 & Yes \\
\hline Ireland & 2007 & 2.61 & 0.3 & 1.47 & 0.17 & 75 & 1500 & No \\
\hline Israel & 2005 & 3.82 & 0.44 & 1.25 & 0.15 & 74 & 1475 & Yes \\
\hline Israel & 2006 & 3.42 & 0.43 & 1.34 & 0.17 & 63 & 1254 & Yes \\
\hline Israel & 2012 & 3.49 & 0.43 & 1.3 & 0.16 & 65 & 1305 & Yes \\
\hline Israel & 2013 & 3.15 & 0.37 & 1.24 & 0.14 & 73 & 1451 & Yes \\
\hline Israel & 2014 & 4.76 & 0.59 & 1.69 & 0.21 & 66 & 1330 & Yes \\
\hline Israel & 2015 & 4.17 & 0.52 & 1.36 & 0.17 & 65 & 1301 & Yes \\
\hline Israel & 2016 & 4.23 & 0.54 & 2.14 & 0.27 & 61 & 1215 & Yes \\
\hline Israel & 2017 & 3.39 & 0.44 & 1.56 & 0.2 & 59 & 1173 & Yes \\
\hline Israel & 2018 & 3.85 & 0.48 & 1.58 & 0.2 & 64 & 1271 & Yes \\
\hline Italy & 1986 & 3.17 & 0.24 & 1.85 & 0.14 & 174 & 3474 & Yes \\
\hline Italy & 1987 & 3.51 & 0.2 & 1.66 & 0.1 & 302 & 6045 & Yes \\
\hline Italy & 1989 & 3.95 & 0.23 & 1.56 & 0.09 & 293 & 5865 & Yes \\
\hline Italy & 1991 & 4.43 & 0.26 & 1.64 & 0.1 & 291 & 5827 & Yes \\
\hline Italy & 1993 & 3.76 & 0.23 & 1.52 & 0.09 & 272 & 5444 & Yes \\
\hline Italy & 1995 & 3.24 & 0.2 & 1.62 & 0.1 & 274 & 5487 & Yes \\
\hline Italy & 1998 & 3.37 & 0.22 & 1.46 & 0.09 & 244 & 4876 & Yes \\
\hline Italy & 2000 & 3.05 & 0.19 & 1.33 & 0.08 & 264 & 5280 & Yes \\
\hline Italy & 2004 & 2.39 & 0.15 & 1.52 & 0.1 & 246 & 4913 & Yes \\
\hline Italy & 2008 & 3.13 & 0.2 & 1.44 & 0.09 & 239 & 4778 & Yes \\
\hline Italy & 2010 & 3.35 & 0.22 & 1.34 & 0.09 & 236 & 4719 & Yes \\
\hline Italy & 2014 & 2.75 & 0.19 & 1.61 & 0.11 & 220 & 4402 & Yes \\
\hline Italy & 2016 & 2.68 & 0.19 & 1.5 & 0.11 & 193 & 3853 & Yes \\
\hline Luxembourg & 2007 & 3.26 & 0.32 & 1.61 & 0.16 & 104 & 2085 & Yes \\
\hline Luxembourg & 2010 & 3.43 & 0.26 & 1.71 & 0.13 & 175 & 3494 & Yes \\
\hline Luxembourg & 2013 & 3.68 & 0.33 & 1.59 & 0.14 & 127 & 2534 & No \\
\hline Mexico & 2004 & 2.58 & 0.35 & 1.58 & 0.22 & 53 & 1055 & Yes \\
\hline Mexico & 2008 & 2.21 & 0.24 & 1.43 & 0.16 & 82 & 1635 & Yes \\
\hline
\end{tabular}


Table 3: Hypothesis testing of $\widehat{\alpha}_{\text {lab }}=\widehat{\alpha}_{\text {cap }}$.

\begin{tabular}{|c|c|c|c|c|c|c|c|c|}
\hline Country & Year & $\widehat{\alpha}_{\text {lab }}$ & s.e. & $\widehat{\alpha}_{\text {cap }}$ & s.e. & $k$ & $N$ & Reject $H_{0}$ ? \\
\hline Mexico & 2010 & 2.64 & 0.32 & 1.64 & 0.2 & 66 & 1323 & Yes \\
\hline Mexico & 2016 & 1.89 & 0.15 & 1.51 & 0.12 & 159 & 3186 & No \\
\hline Mexico & 2018 & 1.82 & 0.14 & 1.59 & 0.12 & 169 & 3389 & $\mathrm{No}$ \\
\hline Netherlands & 1990 & 3.75 & 0.33 & 1.38 & 0.12 & 128 & 2570 & Yes \\
\hline Netherlands & 1993 & 4.16 & 0.38 & 1.23 & 0.11 & 121 & 2423 & Yes \\
\hline Netherlands & 1999 & 4.21 & 0.37 & 1.27 & 0.11 & 128 & 2563 & Yes \\
\hline Netherlands & 2004 & 3.41 & 0.18 & 1.36 & 0.07 & 358 & 7166 & Yes \\
\hline Netherlands & 2007 & 3.17 & 0.16 & 0.98 & 0.05 & 401 & 8011 & Yes \\
\hline Netherlands & 2010 & 3.63 & 0.18 & 1.37 & 0.07 & 400 & 8001 & Yes \\
\hline Netherlands & 2013 & 3.62 & 0.18 & 1.3 & 0.07 & 390 & 7808 & Yes \\
\hline Norway & 1979 & 1.8 & 0.1 & 1.71 & 0.1 & 302 & 6048 & No \\
\hline Norway & 1986 & 5.11 & 0.45 & 1.89 & 0.17 & 129 & 2588 & Yes \\
\hline Norway & 1991 & 3.83 & 0.2 & 1.76 & 0.09 & 368 & 7361 & Yes \\
\hline Norway & 1995 & 3.45 & 0.17 & 1.14 & 0.06 & 401 & 8027 & Yes \\
\hline Norway & 2000 & 3.18 & 0.13 & 0.88 & 0.04 & 574 & 11474 & Yes \\
\hline Norway & 2004 & 3.98 & 0.17 & 0.77 & 0.03 & 547 & 10947 & Yes \\
\hline Norway & 2007 & 3.74 & 0.04 & 1.11 & 0.01 & 8485 & 169708 & Yes \\
\hline Norway & 2010 & 3.55 & 0.04 & 0.86 & 0.01 & 8861 & 177229 & Yes \\
\hline Norway & 2013 & 3.35 & 0.04 & 0.83 & 0.01 & 9157 & 183146 & Yes \\
\hline Norway & 2016 & 3.45 & 0.04 & 0.72 & 0.01 & 9371 & 187424 & Yes \\
\hline Palestine & 2017 & 2.64 & 0.37 & 1.43 & 0.2 & 50 & 1000 & Yes \\
\hline Peru & 2004 & 2.5 & 0.23 & 1.75 & 0.16 & 123 & 2463 & Yes \\
\hline Peru & 2007 & 3.05 & 0.26 & 1.69 & 0.15 & 133 & 2667 & Yes \\
\hline Peru & 2010 & 2.78 & 0.22 & 1.66 & 0.13 & 162 & 3239 & Yes \\
\hline Peru & 2013 & 3.72 & 0.27 & 1.68 & 0.12 & 196 & 3930 & Yes \\
\hline Peru & 2016 & 2.92 & 0.19 & 1.94 & 0.12 & 241 & 4813 & Yes \\
\hline Russia & 2013 & 4.25 & 0.29 & 1.67 & 0.11 & 218 & 4360 & Yes \\
\hline Russia & 2014 & 5.03 & 0.34 & 1.79 & 0.12 & 221 & 4412 & Yes \\
\hline Russia & 2015 & 4.89 & 0.29 & 1.65 & 0.1 & 288 & 5752 & No \\
\hline Russia & 2016 & 5.19 & 0.19 & 1.91 & 0.07 & 786 & 15716 & No \\
\hline Russia & 2017 & 5.54 & 0.33 & 2.42 & 0.14 & 284 & 5671 & No \\
\hline Slovakia & 2010 & 3.49 & 0.49 & 0.96 & 0.13 & 51 & 1024 & Yes \\
\hline Slovakia & 2013 & 2.73 & 0.34 & 0.84 & 0.1 & 64 & 1289 & Yes \\
\hline Slovakia & 2014 & 4.51 & 0.56 & 1.4 & 0.18 & 64 & 1285 & No \\
\hline Slovakia & 2015 & 4.69 & 0.58 & 0.93 & 0.11 & 66 & 1317 & Yes \\
\hline Slovakia & 2016 & 5.46 & 0.72 & 0.87 & 0.12 & 57 & 1139 & No \\
\hline Slovakia & 2017 & 6.98 & 0.94 & 0.93 & 0.13 & 55 & 1105 & No \\
\hline Slovakia & 2018 & 7.55 & 1.03 & 0.69 & 0.09 & 54 & 1079 & Yes \\
\hline Slovenia & 2012 & 6.11 & 0.64 & 1.43 & 0.15 & 92 & 1841 & Yes \\
\hline Slovenia & 2015 & 5.73 & 0.62 & 1.09 & 0.12 & 84 & 1673 & Yes \\
\hline South Korea & 2006 & 4.67 & 0.32 & 1.69 & 0.11 & 218 & 4353 & No \\
\hline South Korea & 2008 & 4.2 & 0.31 & 1.7 & 0.13 & 181 & 3616 & No \\
\hline
\end{tabular}


Table 3: Hypothesis testing of $\widehat{\alpha}_{\text {lab }}=\widehat{\alpha}_{\text {cap }}$.

\begin{tabular}{|c|c|c|c|c|c|c|c|c|}
\hline Country & Year & $\widehat{\alpha}_{\text {lab }}$ & s.e. & $\widehat{\alpha}_{\text {cap }}$ & s.e. & $k$ & $N$ & Reject $H_{0}$ ? \\
\hline South Korea & 2010 & 4.38 & 0.36 & 1.62 & 0.13 & 150 & 3003 & No \\
\hline South Korea & 2012 & 3.79 & 0.29 & 1.58 & 0.12 & 166 & 3329 & No \\
\hline South Korea & 2014 & 5.89 & 0.44 & 1.39 & 0.1 & 176 & 3526 & Yes \\
\hline South Korea & 2016 & 3.95 & 0.31 & 1.33 & 0.1 & 164 & 3282 & Yes \\
\hline Spain & 1980 & 4.21 & 0.49 & 2.07 & 0.24 & 75 & 1503 & No \\
\hline Spain & 1990 & 3.84 & 0.27 & 1.58 & 0.11 & 202 & 4036 & Yes \\
\hline Spain & 1995 & 3.46 & 0.33 & 1.57 & 0.15 & 112 & 2250 & Yes \\
\hline Spain & 2000 & 3.19 & 0.24 & 1.09 & 0.08 & 177 & 3549 & Yes \\
\hline Spain & 2004 & 4.22 & 0.28 & 1.32 & 0.09 & 222 & 4433 & Yes \\
\hline Spain & 2007 & 4.3 & 0.26 & 1.41 & 0.09 & 266 & 5327 & Yes \\
\hline Spain & 2010 & 6.08 & 0.49 & 1.79 & 0.15 & 152 & 3043 & Yes \\
\hline Spain & 2013 & 3.59 & 0.2 & 1.69 & 0.09 & 334 & 6681 & Yes \\
\hline Spain & 2016 & 3.44 & 0.18 & 1.51 & 0.08 & 373 & 7451 & Yes \\
\hline Sweden & 1975 & 3.93 & 0.2 & 1.54 & 0.08 & 392 & 7845 & Yes \\
\hline Sweden & 1981 & 4.56 & 0.26 & 2.47 & 0.14 & 305 & 6092 & Yes \\
\hline Sweden & 1987 & 4.71 & 0.24 & 1.77 & 0.09 & 398 & 7953 & Yes \\
\hline Sweden & 1992 & 4.49 & 0.19 & 1.98 & 0.08 & 541 & 10824 & Yes \\
\hline Sweden & 1995 & 3.97 & 0.16 & 1.63 & 0.07 & 583 & 11655 & Yes \\
\hline Sweden & 2000 & 3.6 & 0.16 & 1.26 & 0.06 & 516 & 10319 & Yes \\
\hline Sweden & 2005 & 3.15 & 0.13 & 1.07 & 0.04 & 598 & 11951 & Yes \\
\hline Switzerland & 1982 & 2.05 & 0.14 & 1.34 & 0.09 & 212 & 4233 & Yes \\
\hline Switzerland & 1992 & 3.55 & 0.24 & 1.3 & 0.09 & 224 & 4486 & Yes \\
\hline Switzerland & 2000 & 3.29 & 0.29 & 1.4 & 0.12 & 132 & 2646 & Yes \\
\hline Switzerland & 2002 & 3.53 & 0.31 & 1.56 & 0.14 & 129 & 2578 & Yes \\
\hline Switzerland & 2004 & 4.41 & 0.38 & 1.38 & 0.12 & 132 & 2648 & Yes \\
\hline Switzerland & 2006 & 3.07 & 0.21 & 1.21 & 0.08 & 210 & 4206 & Yes \\
\hline Switzerland & 2007 & 2.74 & 0.17 & 1.22 & 0.08 & 253 & 5057 & Yes \\
\hline Switzerland & 2008 & 3.01 & 0.19 & 1.11 & 0.07 & 250 & 5004 & Yes \\
\hline Switzerland & 2009 & 2.96 & 0.18 & 1.22 & 0.07 & 270 & 5396 & Yes \\
\hline Switzerland & 2010 & 2.92 & 0.17 & 1.14 & 0.07 & 288 & 5759 & Yes \\
\hline Switzerland & 2011 & 3.2 & 0.19 & 1.25 & 0.07 & 286 & 5714 & Yes \\
\hline Switzerland & 2012 & 3.28 & 0.2 & 1.25 & 0.08 & 274 & 5471 & Yes \\
\hline Switzerland & 2013 & 3.45 & 0.22 & 1.4 & 0.09 & 255 & 5097 & Yes \\
\hline Switzerland & 2014 & 3.09 & 0.18 & 1.31 & 0.08 & 284 & 5672 & Yes \\
\hline Switzerland & 2015 & 3.18 & 0.18 & 1.4 & 0.08 & 297 & 5947 & Yes \\
\hline Switzerland & 2016 & 3.07 & 0.17 & 1.43 & 0.08 & 316 & 6310 & Yes \\
\hline Switzerland & 2017 & 3.19 & 0.2 & 1.46 & 0.09 & 252 & 5048 & Yes \\
\hline Taiwan & 1981 & 4.5 & 0.19 & 1.53 & 0.07 & 532 & 10635 & Yes \\
\hline Taiwan & 1986 & 3.88 & 0.15 & 1.34 & 0.05 & 643 & 12864 & Yes \\
\hline Taiwan & 1991 & 4.11 & 0.15 & 1.41 & 0.05 & 749 & 14978 & Yes \\
\hline Taiwan & 1995 & 4.29 & 0.16 & 1.77 & 0.07 & 681 & 13619 & Yes \\
\hline Taiwan & 1997 & 4.27 & 0.17 & 1.83 & 0.07 & 629 & 12572 & Yes \\
\hline
\end{tabular}


Table 3: Hypothesis testing of $\widehat{\alpha}_{\text {lab }}=\widehat{\alpha}_{\text {cap }}$.

\begin{tabular}{|c|c|c|c|c|c|c|c|c|}
\hline Country & Year & $\widehat{\alpha}_{\text {lab }}$ & s.e. & $\widehat{\alpha}_{\text {cap }}$ & s.e. & $k$ & $N$ & Reject $H_{0}$ ? \\
\hline Taiwan & 2000 & 4.19 & 0.17 & 1.76 & 0.07 & 615 & 12301 & Yes \\
\hline Taiwan & 2005 & 4.17 & 0.17 & 1.8 & 0.07 & 595 & 11903 & Yes \\
\hline Taiwan & 2007 & 3.82 & 0.16 & 1.75 & 0.07 & 602 & 12042 & Yes \\
\hline Taiwan & 2010 & 3.85 & 0.15 & 1.74 & 0.07 & 637 & 12748 & Yes \\
\hline Taiwan & 2013 & 3.85 & 0.15 & 1.55 & 0.06 & 665 & 13300 & Yes \\
\hline Taiwan & 2016 & 3.88 & 0.15 & 1.66 & 0.06 & 682 & 13648 & Yes \\
\hline United Kingdom & 1969 & 3.73 & 0.26 & 1.11 & 0.08 & 205 & 4102 & Yes \\
\hline United Kingdom & 1974 & 3.56 & 0.27 & 1.35 & 0.1 & 177 & 3547 & Yes \\
\hline United Kingdom & 1979 & 5.03 & 0.34 & 1.34 & 0.09 & 214 & 4280 & Yes \\
\hline United Kingdom & 1986 & 4.48 & 0.3 & 1.79 & 0.12 & 226 & 4515 & Yes \\
\hline United Kingdom & 1991 & 3.56 & 0.24 & 1.69 & 0.11 & 222 & 4445 & Yes \\
\hline United Kingdom & 1994 & 2.99 & 0.11 & 1.56 & 0.06 & 781 & 15625 & Yes \\
\hline United Kingdom & 1995 & 3.09 & 0.11 & 1.53 & 0.05 & 789 & 15781 & Yes \\
\hline United Kingdom & 1996 & 2.97 & 0.11 & 1.53 & 0.06 & 770 & 15401 & Yes \\
\hline United Kingdom & 1997 & 2.81 & 0.1 & 1.48 & 0.05 & 728 & 14554 & Yes \\
\hline United Kingdom & 1998 & 2.87 & 0.11 & 1.47 & 0.06 & 699 & 13980 & Yes \\
\hline United Kingdom & 1999 & 2.6 & 0.09 & 1.41 & 0.05 & 764 & 15289 & Yes \\
\hline United Kingdom & 2000 & 2.33 & 0.09 & 1.42 & 0.05 & 732 & 14636 & Yes \\
\hline United Kingdom & 2001 & 2.47 & 0.09 & 1.42 & 0.05 & 794 & 15887 & Yes \\
\hline United Kingdom & 2002 & 2.9 & 0.1 & 1.3 & 0.04 & 898 & 17957 & Yes \\
\hline United Kingdom & 2003 & 2.89 & 0.1 & 1.28 & 0.04 & 886 & 17714 & Yes \\
\hline United Kingdom & 2004 & 2.64 & 0.09 & 1.26 & 0.04 & 867 & 17337 & Yes \\
\hline United Kingdom & 2005 & 2.71 & 0.09 & 1.4 & 0.05 & 872 & 17447 & Yes \\
\hline United Kingdom & 2006 & 2.51 & 0.09 & 1.42 & 0.05 & 796 & 15913 & Yes \\
\hline United Kingdom & 2007 & 2.97 & 0.11 & 1.34 & 0.05 & 766 & 15327 & Yes \\
\hline United Kingdom & 2008 & 2.92 & 0.12 & 1.32 & 0.05 & 586 & 11718 & Yes \\
\hline United Kingdom & 2009 & 2.77 & 0.12 & 1.3 & 0.06 & 526 & 10528 & Yes \\
\hline United Kingdom & 2010 & 3.15 & 0.14 & 1.34 & 0.06 & 492 & 9839 & Yes \\
\hline United Kingdom & 2011 & 3.37 & 0.17 & 1.4 & 0.07 & 391 & 7823 & Yes \\
\hline United Kingdom & 2012 & 2.97 & 0.15 & 1.32 & 0.07 & 374 & 7479 & Yes \\
\hline United Kingdom & 2013 & 3.48 & 0.18 & 1.5 & 0.08 & 386 & 7715 & Yes \\
\hline United Kingdom & 2014 & 3.03 & 0.15 & 1.46 & 0.07 & 396 & 7922 & Yes \\
\hline United Kingdom & 2015 & 3.07 & 0.16 & 1.48 & 0.08 & 383 & 7663 & Yes \\
\hline United Kingdom & 2016 & 3.03 & 0.16 & 1.32 & 0.07 & 367 & 7340 & Yes \\
\hline United Kingdom & 2017 & 3.26 & 0.17 & 1.47 & 0.08 & 348 & 6965 & Yes \\
\hline United Kingdom & 2018 & 3.03 & 0.16 & 1.59 & 0.08 & 353 & 7062 & Yes \\
\hline United States & 1974 & 3.86 & 0.23 & 1.51 & 0.09 & 278 & 5558 & Yes \\
\hline United States & 1979 & 3.7 & 0.08 & 1.46 & 0.03 & 2237 & 44749 & Yes \\
\hline United States & 1986 & 3.36 & 0.08 & 1.64 & 0.04 & 1914 & 38274 & Yes \\
\hline United States & 1991 & 3.45 & 0.08 & 1.54 & 0.04 & 1944 & 38871 & Yes \\
\hline United States & 1992 & 3.14 & 0.07 & 1.49 & 0.03 & 1907 & 38137 & Yes \\
\hline United States & 1993 & 2.51 & 0.06 & 1.46 & 0.03 & 1863 & 37252 & Yes \\
\hline
\end{tabular}


Table 3: Hypothesis testing of $\widehat{\alpha}_{\text {lab }}=\widehat{\alpha}_{\text {cap }}$.

\begin{tabular}{|c|c|c|c|c|c|c|c|c|}
\hline Country & Year & $\widehat{\alpha}_{\text {lab }}$ & s.e. & $\widehat{\alpha}_{\text {cap }}$ & s.e. & $k$ & $N$ & Reject $H_{0}$ ? \\
\hline United States & 1994 & 2.43 & 0.06 & 1.45 & 0.03 & 1868 & 37355 & Yes \\
\hline United States & 1995 & 2.45 & 0.06 & 1.48 & 0.04 & 1604 & 32076 & Yes \\
\hline United States & 1996 & 2.34 & 0.06 & 1.51 & 0.04 & 1558 & 31165 & Yes \\
\hline United States & 1997 & 2.29 & 0.06 & 1.47 & 0.04 & 1546 & 30913 & Yes \\
\hline United States & 1998 & 2.32 & 0.06 & 1.45 & 0.04 & 1557 & 31144 & Yes \\
\hline United States & 1999 & 2.41 & 0.06 & 1.44 & 0.04 & 1566 & 31320 & Yes \\
\hline United States & 2000 & 2.19 & 0.05 & 1.4 & 0.03 & 2348 & 46961 & Yes \\
\hline United States & 2001 & 2.23 & 0.05 & 1.31 & 0.03 & 2308 & 46168 & Yes \\
\hline United States & 2002 & 2.29 & 0.05 & 1.35 & 0.03 & 2198 & 43963 & Yes \\
\hline United States & 2003 & 2.35 & 0.05 & 1.37 & 0.03 & 2170 & 43410 & Yes \\
\hline United States & 2004 & 2.39 & 0.05 & 1.33 & 0.03 & 2118 & 42354 & Yes \\
\hline United States & 2005 & 2.27 & 0.05 & 1.42 & 0.03 & 2081 & 41624 & Yes \\
\hline United States & 2006 & 2.27 & 0.05 & 1.46 & 0.03 & 2013 & 40264 & Yes \\
\hline United States & 2007 & 2.34 & 0.05 & 1.49 & 0.03 & 1966 & 39312 & Yes \\
\hline United States & 2008 & 2.35 & 0.05 & 1.32 & 0.03 & 2026 & 40523 & Yes \\
\hline United States & 2009 & 2.26 & 0.05 & 1.33 & 0.03 & 1922 & 38446 & Yes \\
\hline United States & 2010 & 2.56 & 0.06 & 1.41 & 0.03 & 1869 & 37383 & Yes \\
\hline United States & 2011 & 2.29 & 0.05 & 1.4 & 0.03 & 1836 & 36728 & Yes \\
\hline United States & 2012 & 2.33 & 0.05 & 1.56 & 0.04 & 1843 & 36865 & Yes \\
\hline United States & 2013 & 2.4 & 0.07 & 1.4 & 0.04 & 1225 & 24494 & Yes \\
\hline United States & 2014 & 2.37 & 0.05 & 1.41 & 0.03 & 2316 & 46312 & Yes \\
\hline United States & 2015 & 2.32 & 0.05 & 1.36 & 0.03 & 2213 & 44260 & Yes \\
\hline United States & 2016 & 2.29 & 0.05 & 1.42 & 0.03 & 2270 & 45401 & Yes \\
\hline United States & 2017 & 2.42 & 0.05 & 1.45 & 0.03 & 2255 & 45102 & Yes \\
\hline United States & 2018 & 2.26 & 0.05 & 1.34 & 0.03 & 2265 & 45307 & Yes \\
\hline Uruguay & 2004 & 2.53 & 0.32 & 1.81 & 0.23 & 62 & 1241 & No \\
\hline Uruguay & 2007 & 3.26 & 0.22 & 1.53 & 0.11 & 212 & 4236 & Yes \\
\hline Uruguay & 2010 & 3.1 & 0.22 & 1.63 & 0.11 & 204 & 4085 & Yes \\
\hline Uruguay & 2013 & 3.69 & 0.28 & 1.8 & 0.14 & 175 & 3497 & Yes \\
\hline Uruguay & 2016 & 3.53 & 0.26 & 1.69 & 0.13 & 182 & 3632 & Yes \\
\hline Vietnam & 2011 & 3.26 & 0.4 & 1.23 & 0.15 & 68 & 1362 & Yes \\
\hline Vietnam & 2013 & 2.61 & 0.31 & 1.64 & 0.2 & 69 & 1384 & No \\
\hline
\end{tabular}

Note: $\widehat{\alpha}_{\text {lab }}\left(\right.$ resp. $\left.\widehat{\alpha}_{\text {cap }}\right):$ point estimate of Pareto exponent for labor (resp. capital) income; s.e.: standard error $(\widehat{\alpha}(k) / \sqrt{k}) ; k$ : the number of order statistics used for the Hill-estimator; $N$ : the number of positive capital income observations; the last column denotes if $H_{0}$ is rejected. 